\title{
Pseudomonas aeruginosa Modulates the Antiviral Response of Bronchial Epithelial Cells
}

\author{
Michael Sörensen 1,2, Julia Kantorek ${ }^{1}$, Lauren Byrnes ${ }^{1}$, Sébastien Boutin ${ }^{1,3}$, \\ Marcus A. Mall ${ }^{4,5}$, Felix Lasitschka ${ }^{6,7}$, Heike Zabeck ${ }^{8}$, Dao Nguyen ${ }^{9,10}$ and \\ Alexander H. Dalpke ${ }^{1,3,11 *}$
}

${ }^{1}$ Department of Infectious Diseases, Medical Microbiology and Hygiene, University Hospital Heidelberg, Heidelberg, Germany, ${ }^{2}$ Laboratory Enders and Partners, Stuttgart, Germany, ${ }^{3}$ Translational Lung Research Center Heidelberg (TLRC), German Center for Lung Research (DZL). University Hospital Heidelberg. Heidelberg, Germany, ${ }^{4}$ Department of Pediatric Pulmonology, Immunology and Intensive Care Medicine, Charité Universitätsmedizin Berlin, Berlin, Germany, ${ }^{5}$ Berlin Institute of Health (BIH), Berlin, Germany, ${ }^{6}$ Institute of Pathology, University Hospital Heidelberg, Heidelberg, Germany, ${ }^{7} \mathrm{TI}$ Biobanking, German Centre for Infection Research (DZIF), Heidelberg, Germany, ${ }^{8}$ Thoraxklinik, University Hospital Heidelberg, Heidelberg, Germany, ${ }^{9}$ Meakins-Christie Laboratories, Research Institute of the McGill University Health Centre, Montreal, QC, Canada, ${ }^{10}$ Department of Medicine, McGill University, Montreal, QC, Canada, ${ }^{11}$ Institute of Medical Microbiology and Hygiene, Medical Faculty, Technische Universität Dresden, Dresden, Germany

OPEN ACCESS

Edited by:

Amy Rasley,

Lawrence Livermore National Laboratory (DOE), United States

Reviewed by:

Andreas Kupz,

James Cook University, Australia Dane Parker

New Jersey Medical School,

United States

*Correspondence:

Alexander H. Dalpke

alexander.dalpke@ukdd.de

Specialty section: This article was submitted to Microbial Immunology, a section of the journal

Frontiers in Immunology

Received: 27 August 2019 Accepted: 14 January 2020 Published: 04 February 2020

Citation:

Sörensen M, Kantorek J, Byrnes L, Boutin S, Mall MA, Lasitschka F, Zabeck $H$, Nguyen D and Dalpke $A H$ (2020) Pseudomonas aeruginosa Modulates the Antiviral Response of

Bronchial Epithelial Cells.

Front. Immunol. 11:96.

doi: 10.3389/fimmu.2020.00096
Cystic fibrosis (CF) patients frequently acquire Pseudomonas aeruginosa infections that have been associated with a bad prognosis and an increased rate of pulmonary exacerbations. Respiratory viruses can cause exacerbations in chronic pulmonary diseases including COPD or asthma and have been suggested to contribute to exacerbations also in CF. In this study we investigated a possible link between $P$. aeruginosa infection and susceptibility to respiratory viruses. We show that $P$. aeruginosa is able to block the antiviral response of airway epithelial cells thereby promoting virus infection and spread. Mechanistically, $P$. aeruginosa secretes the protease AprA in a LasR dependent manner, which is able of directly degrading epithelial-derived IFN $\lambda$ resulting in inhibition of IFN signaling. In addition, we correlate the virus infection status of CF patients with the ability of patients' $P$. aeruginosa isolates to degrade IFN $\lambda$. In line with this, the infection status of CF patients correlated significantly with the amount of respiratory viruses in sputum. Our data suggest that the interplay between $P$. aeruginosa and respiratory virus infections might partially explain the association of increased rates of pulmonary exacerbations and $P$. aeruginosa infections in CF patients.

Keywords: Pseudomonas aeruginosa, cystic fibrosis, virus, antiviral response, interferon, protease, LasR

\section{INTRODUCTION}

Cystic fibrosis $(\mathrm{CF})$ is an autosomal recessive hereditary disease caused by mutations in the Cystic Fibrosis Transmembrane Conductance Regulator (CFTR) gene. Mutations of CFTR lead to non- or mal-function of all exocrine glands and mucosal surfaces of the human body. Thus, the disease affects various organs including intestine, pancreas and lung (1). Life expectancy of CF patients is severely decreased and this is nowadays mainly dictated by the pulmonary phenotype: CF patients suffer from thickened respiratory mucus causing mucus plugging of the airways, chronic inflammation as well as increased incidence of pulmonary bacterial infections. Infections are 
of polymicrobial nature yet $H$. influenzae, S. aureus, and $P$. aeruginosa are clinically important pathogens in CF lung disease (2). Bacterial airway infection and inflammation associated with reduced mucociliary clearance mediate progressive lung damage and a decline in lung function over time, finally resulting in death due to respiratory failure.

Especially chronic airway infections with $P$. aeruginosa have been correlated with an accelerated loss of lung function $(3,4)$. $P$. aeruginosa infections typically start as intermittent infection with environmental strains that initially are sensitive to antibiotic eradication. However, over time $P$. aeruginosa undergoes adaptive mutations including gain of antibiotic resistance, loss of virulence factors, e.g., proteases or pyocyanin production, and increased alginate synthesis. This favors the establishment of chronic infection and resistance to antibiotic treatment that results in failure of eradication (5). Several secreted proteases of $P$. aeruginosa have been described modulating the inflammatory response of the host. As such, LasB, a protease under the control of the quorum sensing receptor LasR, has been demonstrated to degrade IL-6 and IL-8. This helps $P$. aeruginosa to establish an infection since it blocks the recruitment of leukocytes (6). Also other LasR regulated proteases $(7,8)$, like LasA or AprA, have been demonstrated to degrade cytokines and might act in the same way as LasB (9). Interestingly, as soon as $P$. aeruginosa infection has been established, LasR often acquires loss of function mutations during the transition of intermittent to chronic infections and thereby further boosts pulmonary inflammation (6).

However, the decline in lung function that is associated with development of chronic infection with $P$. aeruginosa is not constant or linear. Instead, periods of relatively stable lung function are interrupted by episodes with an acute drop in lung function, from which full recovery might not be achieved by antibiotic treatment (10). Causes and pathological mechanisms involved in these pulmonary exacerbations are often unclear and bacterial and viral infections have been attributed to it (11). Virus-induced pulmonary exacerbations are wellknown in other lung diseases like COPD or asthma (12). Yet, the importance of viral induced pulmonary exacerbations in CF patients is still unclear $(13,14)$. However, it has been shown that the lung microbiome composition itself is quite resilient and does not change to great extent in most cases of exacerbation $(15,16)$ and therefore the involvement of nonbacterial organisms, including viruses, is likely. The antiviral response is triggered by intracellular recognition of viruses via nucleic acid pattern receptors including TLR3 and RIGI. Activation of these receptors induces an initial type I/III IFN synthesis which subsequently boosts its own production in a positive feedback loop (17). It has been shown that respiratory epithelial cells produce mainly type III IFN and the importance of these proteins in the airways is well-documented $(18,19)$. Moreover, manipulation of type III IFN has been linked to increased susceptibility of asthmatic patients toward human rhinoviruses (hRV) and a contribution to pulmonary exacerbation has been suggested $(20,21)$. Since $P$. aeruginosa and respiratory viruses have been linked to pulmonary exacerbations and in addition, respiratory viruses have been associated with the transition from transient to chronic airway infections with $P$. aeruginosa $(22,23)$ a link between both microorganisms is likely. Therefore, we investigated in this study if $P$. aeruginosa is able to modulate the antiviral response of bronchial epithelial cells and how such interplay might happen at the mechanistical level. In addition we analyzed sputa of CF patients for the presence of respiratory viruses and determined the levels of virus RNA in order to link $P$. aeruginosa to virus infection thus identifying clinical importance of the experimental findings.

\section{RESULTS}

\section{$P$ aeruginosa Inhibits the Antiviral Response of Airway Epithelial Cells}

In order to analyze whether $P$. aeruginosa is able to modulate the antiviral response of bronchial epithelial cells, we prepared control medium or conditioned medium (CM) from two different strains of $P$. aeruginosa, PAO1 (commonly used in research) and Boston (quality control strain), respectively. CM contains soluble factors secreted by $P$. aeruginosa during growth. We focused on soluble factors since $P$. aeruginosa is mostly located intraluminally in CF lungs and direct cell-cell contacts are less common (24). Subsequently, we used CM or control medium to treat airway BEAS2B cells and thereafter infected the cells with hRV (strain RV1b) or RSV (Figure 1A). Subsequently, antiviral responses were analyzed after various incubation times. Induction of the antiviral genes MX1 and OAS1 upon virus infection did not show any significant differences between BEAS2B cells pretreated with CM of $P$. aeruginosa Boston strain (CM-Boston) or control medium (Figure 1B). However, cells treated with $\mathrm{CM}$ of $P$. aeruginosa strain PAO1 (CM-PAO1) showed a significant decrease in the induction of both genes after infection with hRV and RSV, which was most pronounced after $14 \mathrm{~h}$ of infection compared to control medium [fold induction (FI) of MX1: 285 vs. $6, p<0.001$; FI OAS1: 49 vs. $1, p<$ 0.001 ; Figure 1A]. Since effects were stronger after RSV infection all subsequent experiments were done with RSV. Of note, conditioning with $P$. aeruginosa medium alone did not affect MX1 or OAS1 expression (not shown).

As $P$. aeruginosa might act cytotoxic to eukaryotic cells we chose to use only conditioned medium instead of direct bacterial infection and we also controlled viability by annexin $\mathrm{V}$ and propidium iodide staining. Even though we observed some cytotoxic effects at $14 \mathrm{~h}$ we did not detect differences in viability of epithelial cells conditioned with medium from either of the two $P$. aeruginosa strains up to $10 \mathrm{~h}$ (viability was $96 \pm 1.7 \%$ for Boston vs. $96 \pm 2.7 \%$ for PAO1 after hRV infection and $95 \pm 2 \%$ and $96 \pm 3 \%$ after RSV infection, respectively). Therefore, cytotoxic effects can be excluded as an explanation why only PAO1 inhibited the antiviral response. Of note, we did not observe any differences by any CM treatment with respect to the viral load of the primary infected cells indicating that the first infection of the cells was not affected by soluble $P$. aeruginosa factors (Figure S1). Yet, we speculated that the inhibition of the antiviral response by CM-PAO1 (as indicated by reduced ISG induction) may facilitate spread of 

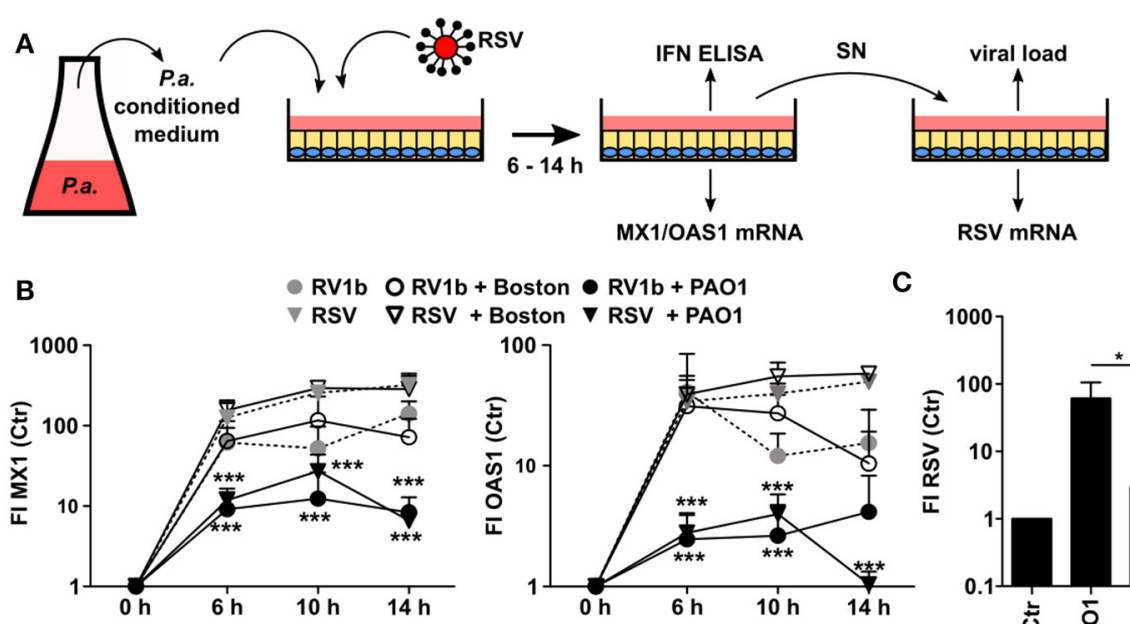

C
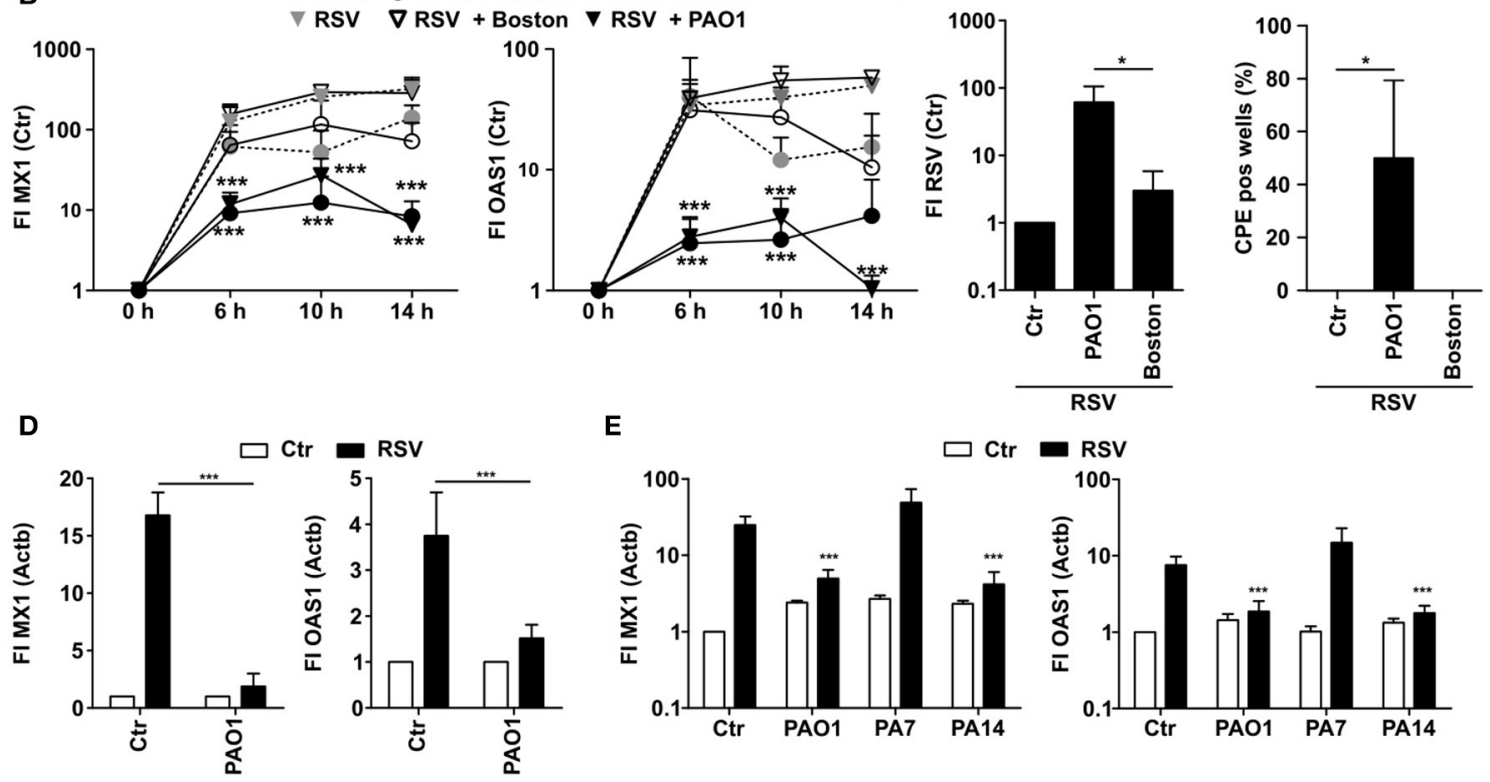

FIGURE 1 | $P$. aeruginosa is able to suppress antiviral response of airway epithelial cells. (A) Cell culture based experimental workflow. (B) BEAS2B cells were pretreated with conditioned medium of $P$. aeruginosa (PAO1 and Boston) or control medium and subsequently infected with RSV or RV1b. Induction of MX1 and OAS1 mRNA were analyzed by qRT-PCR after 6, 10, and 14 h. (C) BEAS2B cells were treated as in (A) and cell culture supernatant of RV1b (human RV) or RSV infected cells (14h) was transferred to new BEAS2B cells. Levels of RV1b (hRV) or RSV mRNA were analyzed by qRT-PCR and the number of wells displaying RV1b or RSV specific cytopathogenic effects (CPE) was determined. (D) Primary HBE cells were pretreated with conditioned medium of $P$. aeruginosa (PAO1) or control medium and subsequently infected with RSV. Induction of MX1 and OAS1 mRNA were analyzed by qRT-PCR after 14 h. (E) BEAS2B cells were pretreated with conditioned medium of $P$. aeruginosa or control medium and subsequently infected with RSV. Induction of MX1 and OAS1 mRNA were analyzed by qRT-PCR after $14 \mathrm{~h}$. All experiments $n=3-4$, ANOVA and Bonferroni post-test was used for statistical analysis. Significant differences were considered at ${ }^{\star} p<0.05$, ${ }^{\star \star} p<0.01$, and ${ }^{* * *} p<0.001$ as compared to the control condition. n.s., not significant.

the virus infection. To analyze the functional relevance of the decreased antiviral response, we therefore challenged another batch of BEAS2B cells with the supernatant of CM-pretreated and RSV infected cells (Figure 1A). In line with a decrease of the antiviral response in CM-PAO1 treated BEAS2B cells, we observed increases in RSV-RNA and RSV-specific cytopathic effects in cells challenged with the supernatant of CM-PAO1 treated cells as compared to control or CM-Boston treated cells (Figure 1C). These results indicate that the repression of the antiviral response by $\mathrm{PAO} 1$ leads to an increase in virus spreading and is therefore of functional relevance. To confirm the effects in primary cells we repeated the main experiment in primary human bronchial epithelial cells (hBrEpC). In line with our observations in BEAS2B cells, PAO1 was also able to repress $\mathrm{RSV}$ induced antiviral responses in hBrEpC (Figure 1D). It is known that $P$. aeruginosa can be classified into three different phylogenetic groups (25), represented by PA14, PAO1, and PA7 for group 1, 2, and 3, respectively. Like PAO1 PA14 but not PA7 was also able to repress the antiviral response toward RSV
(Figure 1E) indicating that the inhibition of an antiviral response is not restricted to a specific phylogenetic group.

\section{$P$. aeruginosa Blocks IFN $\lambda$ Activity}

To elucidate how PAO1 inhibits induction of antiviral gene expression, we first analyzed IFN production in PAO1-CM treated cells after infection with RSV. IFN $\lambda$ is the main IFN produced by airway epithelial cells upon viral infections, whereas RSV did not induce IFN $\alpha$ mRNA and only moderate levels of IFN $\beta$ mRNA (Figure S2). Interestingly, early IFN $\lambda$ mRNA levels at $6 \mathrm{~h}$ p.i. were similar in control or CM-treated cells suggesting that initial virus recognition was not affected. However, at 10 and $14 \mathrm{~h}$ p.i. IFN $\lambda$ mRNA levels decreased significantly in PAO1-CM treated cells (Figure $2 \mathrm{~A}$ ). Importantly, virtually no IFN $\lambda$ protein was detectable in the cell culture supernatant of PAO1-CM treated cells at $14 \mathrm{~h}$ (Figure 2B) indicating that despite an early mRNA induction, positive amplification, and final production of IFN $\lambda$ protein was blocked. For virus infection we were not able to detect functional IFN $\beta$ protein (data not shown). These findings 

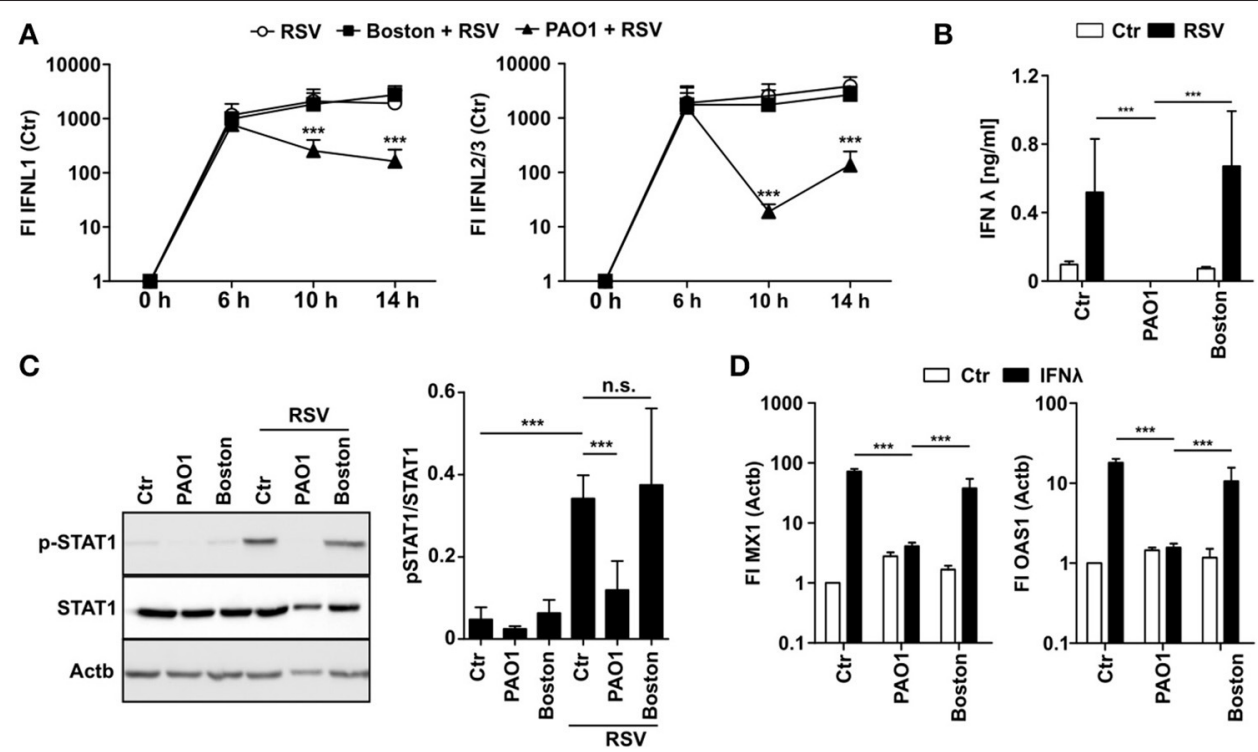

FIGURE $2 \mid P$. aeruginosa is able to block IFN induction and signaling. (A) BEAS2B cells were pretreated with conditioned medium of $P$. aeruginosa (PAO1 and Boston) or control medium and subsequently infected with RSV. Induction of IFNL1 and IFNL2/3 mRNA were analyzed by qRT-PCR after 6, 10, and 14 h. (B) BEAS2B cells were treated as in (A) and IFN $\lambda$ levels of cell culture supernatant (14 h) were analyzed by ELISA. (C) BEAS2B cells were treated as in (A) and p-STAT1 levels of cells $(6 \mathrm{~h})$ were analyzed in cell lysates by western blot. (D) BEAS2B cells were pretreated as in (A). Cells were then stimulated with recombinant IFN $\lambda$ ( 5,000 pg/ml) and induction of MX1 and OAS1 were analyzed after $14 \mathrm{~h}$ by qRT-PCR. All experiments $n=3-4$, ANOVA and Bonferroni post-test was used for statistical analysis. Significant differences were considered at ${ }^{*} p<0.05$, ${ }^{* *} p<0.01$, and ${ }^{\star * *} p<0.001$ as compared to the control condition. n.s., not significant.

may be explained by PAO1 modulating IFN $\lambda$ protein production, secretion, stability, or signaling, thereby blocking the secondary positive feedback loop important for sustained and efficient IFN signaling. In line, STAT1 phosphorylation as an endogenous indicator of IFN signaling was missing in the presence of PAO1$\mathrm{CM}$ but not with Boston-CM (Figure 2C). Next, we tested if recombinant exogenous IFN $\lambda$ could overcome PAO1-CM effects as should be the case if production and secretion would be hampered: Surprisingly, addition of exogenous IFN $\lambda$ resulted in MX1 and OAS1 induction in control cells and Boston-CM treated cells, yet in PAO1-conditioned BEASB cells no induction could be observed (Figure 2D). The results indicated that PAO1 could either block the recognition of IFN $\lambda$ by its receptor or destabilize IFN $\lambda$ protein.

\section{$P$. aeruginosa PAO1 Degrades IFN $\lambda$ by Secretion of Proteases}

Since $P$. aeruginosa is known to secret various proteases, we next tested whether CM of $P$. aeruginosa is able to degrade recombinant IFN $\lambda$ directly (Figure 3A). CM of both strains, PAO1 and Boston, degraded recombinant IFN $\lambda$ but PAO1 was much more efficient with complete destruction of added IFN $\lambda$ even after $1 \mathrm{~h}$ of incubation. To elucidate the mechanism of action, we heat treated $\left(10 \mathrm{~min}, 95^{\circ} \mathrm{C}\right.$ ) or filtered (molecular weight cut-off $30 \mathrm{kDa}$ ) the conditioned medium from both $P$. aeruginosa strains (Figures 3B,C). Both treatments were able to restore MX1 and OAS1 induction by RSV in PAO1-conditioned cells indicating that the inhibitory factors in PAO1-CM might be proteins of $<30 \mathrm{kDA}$. We next analyzed the general secretion of proteases by both strains using casein degradation (Figure 3D) or zymography (Figure 3E). Although both strains showed protease secretion, protease activity was much higher in PAO1 (Figure 3D). Zymography also showed that PAO1 had higher AprA and LasA/B activity (as determined by size) whereas the Boston strain only expressed low amounts of AprA (Figure 3E).

\section{P. aeruginosa Isolates From CF Patients With Intermittent, but Not With Chronic Infection Show Inhibition of Antiviral Responses}

It is well-known that $P$. aeruginosa adapts to the lung microenvironment in CF patients by downregulating several virulence factors over time including secreted proteinases when establishing a chronic infection. Therefore, we made use of four longitudinal $P$. aeruginosa pairings from four different $\mathrm{CF}$ patients (CF1 to CF4). All pairings are clonally related as was shown by RFLP before (6) and were isolated from the same patients with at least 8 years time span (Figure 4A). Whereas, the early isolates of each patient showed considerable protease activity, the late-stage isolates had significantly lower protease activity (Figure 4B). Analyzing the effect of the early isolates on the antiviral response to RSV, all isolates were able to suppress the induction of MX1 or OAS1. In line with their reduced protease activity, 3 out of 4 of later isolates displayed a lower or completely missing capacity to suppress the antiviral response (Figure 4C). An exception was isolate CF1.2, but as shown in Figure 4B this isolate also showed only a minor reduction in protease activity. Of note, expression of MX1 or OAS1 correlated significantly with the protease activity measured (Figure 4D). Many of the secreted proteases are under the regulation of the transcription factor LasR. Since LasR is known to become mutated in progressed stages of $P$. aeruginosa infection in $\mathrm{CF}$ 

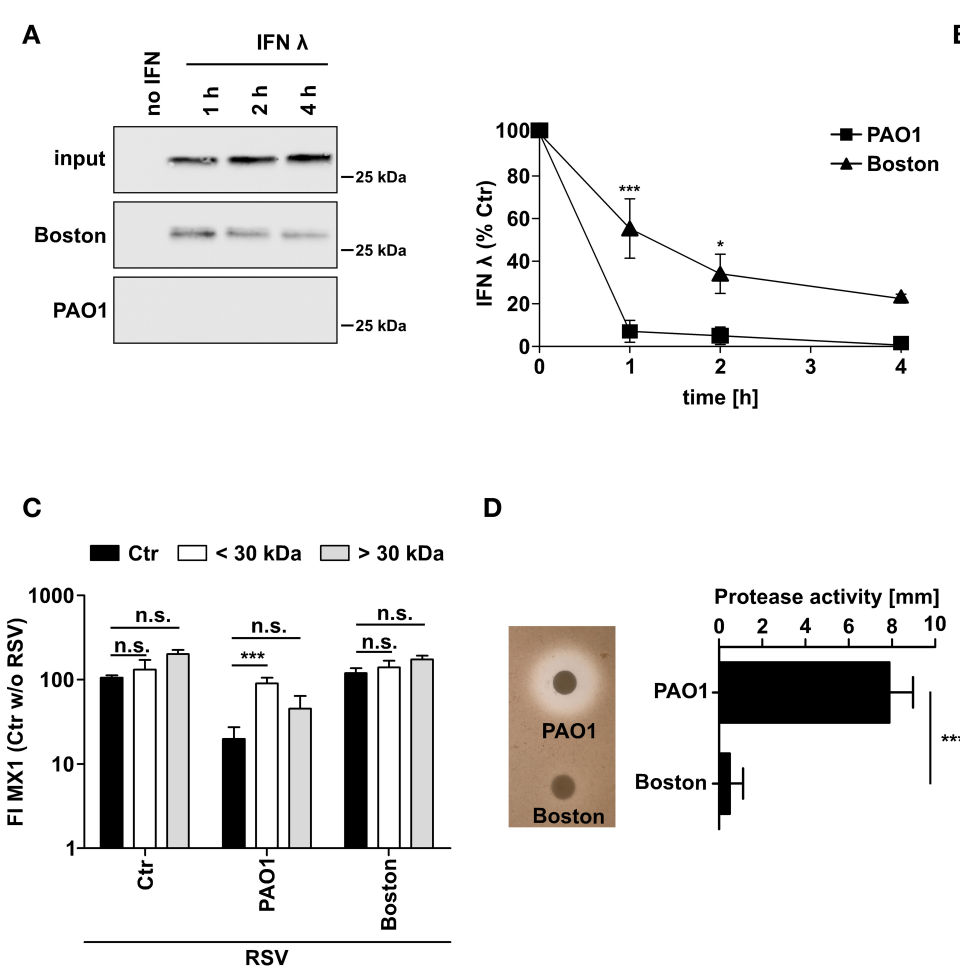

D

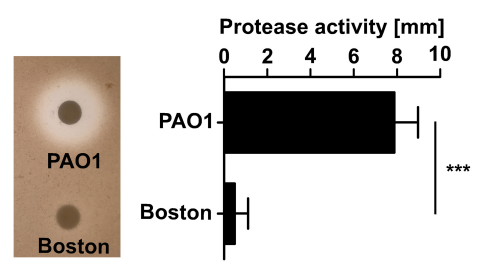

B

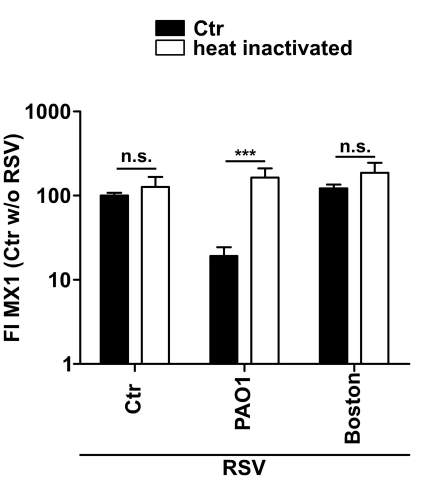

E

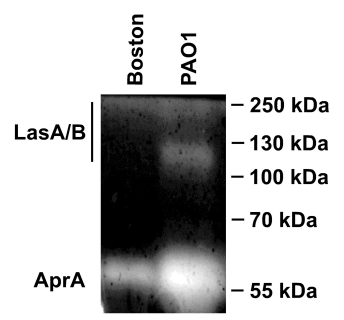

FIGURE $3 \mid P$. aeruginosa secretes a protease degrading directly IFN $\lambda$. (A) Recombinant IFN $\lambda$ was incubated in conditioned medium of $P$. aeruginosa (PAO1 and Boston) or control medium at $37^{\circ} \mathrm{C}$ for 1,2 , or $4 \mathrm{~h}$. Subsequently, levels of IFN $\lambda$ were analyzed by western blot. (B) Conditioned media was heated for 10 min at $95^{\circ} \mathrm{C}$. Subsequently BEAS2B cells were pretreated with heat treated or non-treated conditioned medium of $P$. aeruginosa (PAO1 and Boston) or with control medium and subsequently infected with RSV. Induction of MX1 mRNA was analyzed by qRT-PCR after $14 \mathrm{~h}$ post-infection. (C) Conditioned media was filtered using a cutoff of 30 $\mathrm{kDa}$. Subsequently BEAS2B cells were pretreated with the fraction larger than $30 \mathrm{kDa}$, smaller than $30 \mathrm{kDa}$, non-filtered conditioned medium of $P$. aeruginosa (PAO1 and Boston) or control medium and subsequently infected with RSV. Induction of MX1 mRNA was analyzed by qRT-PCR after $14 \mathrm{~h}$ post-infection. (D) Protease activity in conditioned medium of $P$. aeruginosa (PAO1 and Boston) was assessed using skim-milk agar. (E) Elastase activity in conditioned medium of $P$. aeruginosa (PAO1 and Boston) was assessed by zymography. All experiments $n=3-4$, ANOVA and Bonferroni post-test was used for statistical analysis. Significant differences were considered at ${ }^{*} p<0.05,{ }^{\star \star} p<0.01$, and ${ }^{* \star *} p<0.001$ as compared to the control condition. n.s., not significant.

patients (26), we sequenced LasR of all isolates used (CF1-4). We identified mutations in the late-stage isolates and in $P$. aeruginosa Boston (Figure 4E). Those mutated strains were the strains that had no inhibitory effect on MX1 and OAS induction (Figure 4C). Of note, no mutation of LasR was identified in CF1.2, the only strain that was still able to inhibit the antiviral response. Additionally, a mutation in LasR was detected in the early strain CF2.1 that was the one with low protease activity even at early time of infection (Figure 4B). The mutations were either nonsynonymous mutations (Boston, CF2.1), deletions resulting in a frameshift and nonsense peptide sequence (CF2.2, CF4.2) or a synonymous mutation resulting in a seldom-used codon/t-RNA combination for $P$. aeruginosa (CF3.2) (Figure 4E). In line with this, PA7, a group $3 P$. aeruginosa strain (also not able to suppress antiviral response, Figure 1E), has only 93\% identical nucleotides compared to the reference strain PAO1 which results in three amino acid exchanges $\left(\mathrm{K}_{70}>\mathrm{R} ; \mathrm{S}_{142}>\mathrm{N} ; \mathrm{N}_{182}>\mathrm{S}\right)$.

\section{Inhibition of the Antiviral Response by $P$. aeruginosa Depends on LasR and AprA}

Since the previous data implied an involvement of the quorum sensing protein LasR, we again used further clinical CF isolates $(\mathrm{CFI}-\mathrm{V})$ and their counterparts with a targeted LasR mutation.
In line with the reported importance of LasR in the expression of proteases (6) all LasR deficient CF isolates displayed significantly lower protease activity in CM (Figure 5A). In parallel, all CF isolates with functional LasR were able to suppress the induction of MX1 and OAS1 after RSV infection whereas their LasR deficient counterparts were not (Figure 5B). The most important proteases regulated by LasR are AprA, LasA, LasB, and PrpL. In order to investigate which LasR dependent protease is involved in the modulation of the antiviral response, we used strain PA14 and transposon mutants of PA14 with specific protease deficiency. We observed that even though all protease deficient mutants showed a decrease in total protease activity in CM (Figure 5C), only AprA-deficient PA14 was not able anymore to suppress the induction of antiviral genes MX1 and OAS1 (Figure 5D). These observations indicate that the LasR-regulated protease AprA degrades IFN $\lambda$, thereby blocking the induction of the antiviral response upon RSV infection.

\section{CF Patients With Intermittent $P$. aeruginosa Infection Are at Higher Risk to Be Infected With Human Rhinovirus}

To examine the biological significance of the above findings, we next analyzed a collection of $P$. aeruginosa isolates obtained 
A

\begin{tabular}{|c|c|c|c|}
\hline & Isolate1 & $\rightarrow$ Isolate2 & $\begin{array}{c}\text { timespan between } \\
\text { isolate1 and isolate2 }\end{array}$ \\
\hline Patient 10 & CF1.1 & $\rightarrow \quad$ CF1.2 & 11 years \\
\hline Patient 2 $\square$ & CF2.1 & $\rightarrow \quad$ CF2.2 & 15 years \\
\hline Patient $3 \square$ & CF3.1 & $\rightarrow \quad$ CF 3.2 & 21 years \\
\hline Patient $4 \square$ & CF4.1 & $\rightarrow \quad$ CF 4.2 & 8 years \\
\hline
\end{tabular}

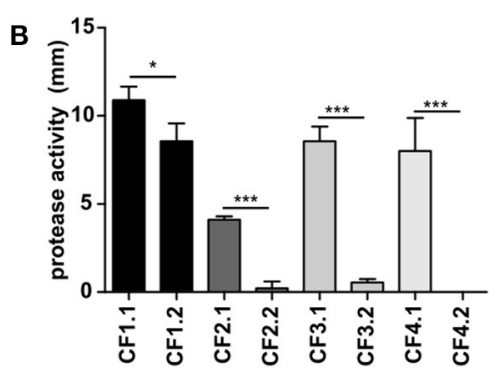

D
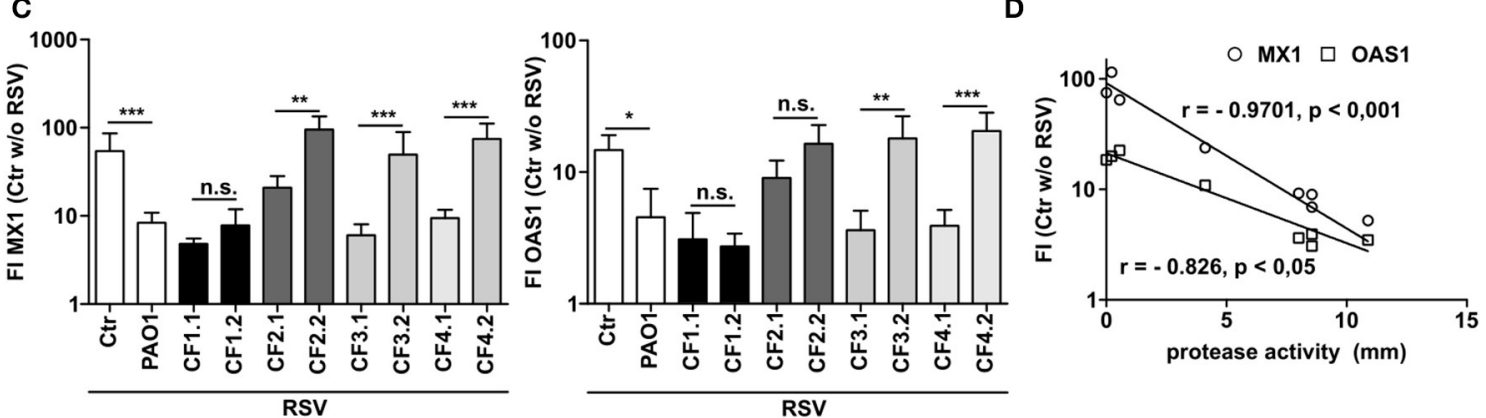

E

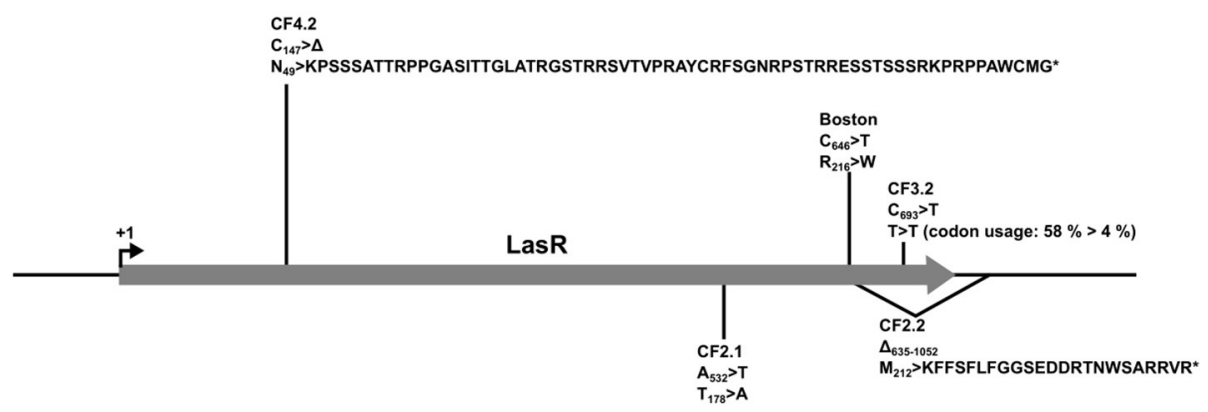

FIGURE 4 | Late $P$. aeruginosa CF isolates display low protease activity and decreased ability to inhibit antiviral response. (A) Characteristics of longitudinal isolates of $P$. aeruginosa from CF patients. (B) Protease activity of $P$. aeruginosa CF isolates was assessed using skim milk agar. (C) BEAS2B cells were pretreated with conditioned medium of $P$. aeruginosa from (A) or control medium and subsequently infected with RSV. Induction of MX1 and OAS1 mRNA were analyzed by qRT-PCR after $14 \mathrm{~h}$. (D) Spearman correlation of protease activity and induction of MX1 or OAS1 mRNA measured in (B,C). (E) LasR genetic mutations and resulting changes in protein translation found in CF isolates described in (A). All experiments $n=4$, ANOVA and Bonferroni post-test was used for statistical analysis. Significant differences were considered at ${ }^{\star} p<0.05,{ }^{* *} p<0.01$, and ${ }^{* \star *} p<0.001$ as compared to the control condition. n.s., not significant.

from $C F$ patients at various stages of $P$. aeruginosa infection. We measured total protease activity of $P$. aeruginosa isolates and their ability to degrade recombinant IFN $\lambda$. We observed a strong correlation $(R=0.62)$ and significant interdependency between protease activity and IFN $\lambda$ degradation (Figure 6A). Moreover, when grouping the $P$. aeruginosa isolates according to their stage of infection (intermittent/early or chronic infection/late) we observed that especially $P$. aeruginosa of intermittent infected patients were able to degrade IFN $\lambda$ (Figure 6B). This could indicate that especially intermittent infected CF patients are prone to acquire respiratory virus infections. Therefore, we checked which viruses are present in respiratory material (nose or throat swabs, sputum) of CF patients (Figure 6C). Using a multiplex diagnostic virus panel, we screened 818 samples of 526 visits. We could detect viruses in 162 samples (30.85\%). Most of the viruses found in these patients were human rhinoviruses (hRV) (66\%) whereas RSV was only found to a lower extent and at similar frequency to Influenza, Adenovirus or Parainfluenza Virus (3.7-7.4\%). Since hRV was the most prevalent virus detected and $P$. aeruginosa was also able to suppress hRV induced antiviral response (Figure 1B), we decided to further analyze the presence of hRV in the sputum of these patients, since $P$. aeruginosa can be reliably detected in this material. In accordance with the literature we did not detect any difference between the three groups if all samples (nose, throat, and sputum) from one patient were considered (Figure 6D). However, restriction of the analysis to lower airways' sputum samples from CF patients $(n=499)$ revealed that the prevalence of hRV detection was significantly higher $(p=0.037)$ in intermittent $P$. aeruginosa infected CF patients (16.5\%) than in chronic patients $(8.5 \%)$ or in patients not infected with $P$. aeruginosa (11.0\%) (Figure 6E). In line with this, the detectable virus load indicated by the hRV Ct value by RT-PCR was highest in samples of intermittent infected $\mathrm{CF}$ patients, which were culture-positive for $P$. aeruginosa at 


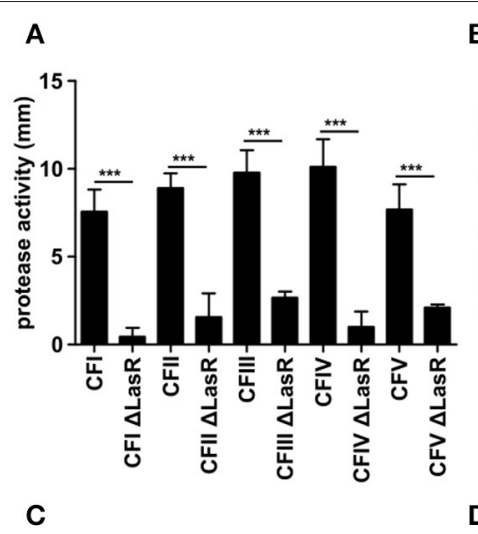

B
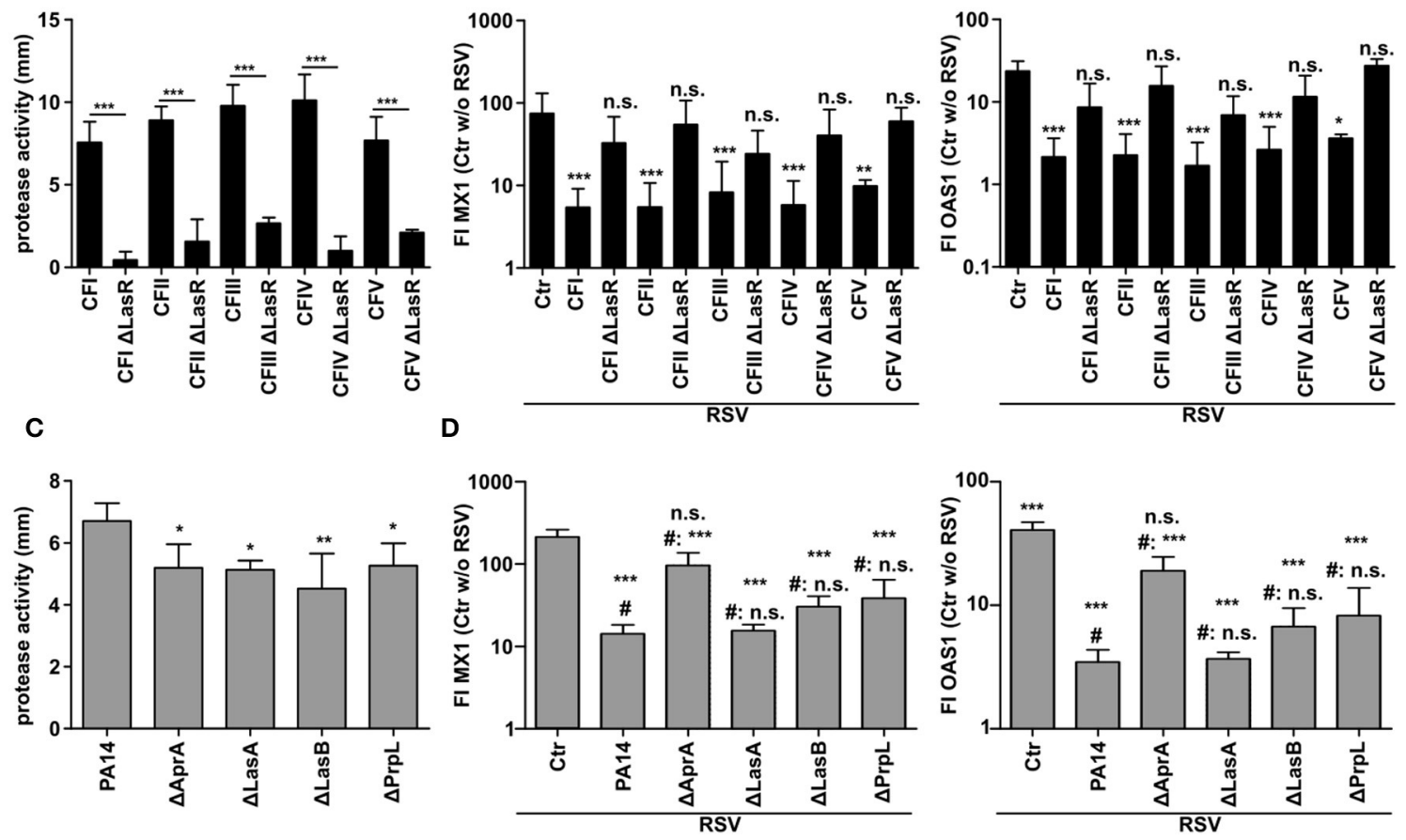

FIGURE 5 | Inhibition of antiviral response by $P$. aeruginosa depends on quorum sensing and the secreted protease AprA. (A) Protease activity of $P$. aeruginosa CF isolates and corresponding LasR deficient strains was assessed using a skim milk agar assay. (B) BEAS2B cells were pretreated with conditioned medium of $P$. aeruginosa from (A) or control medium and subsequently infected with RSV. Induction of MX1 and OAS1 mRNA were analyzed by qRT-PCR after 14 h. (C) Protease activity of $P$. aeruginosa strain PA14 and corresponding protease deficient strains was assessed using skim milk agar. (D) BEAS2B cells were pretreated with conditioned medium of $P$. aeruginosa from (C) or control medium and subsequently infected with RSV. Induction of MX1 and OAS1 mRNA were analyzed by qRT-PCR after $14 \mathrm{~h}$. All experiments $n=4-5$, ANOVA and Bonferroni post-test was used for statistical analysis. (D) Statistical analysis was done in comparison to the control (ctr) or to treatment with PA14 (indicated by prefix \#). Significant differences were considered at ${ }^{*} p<0.05$, ${ }^{* *} p<0.01$, and ${ }^{* \star *} p<0.001$ as compared to the control condition. n.s., not significant.

the time of sampling (Figure 6F). These observations in clinical samples indicate that $P$. aeruginosa may also be able to modulate the antiviral response in vivo in the clinical setting of CF.

\section{DISCUSSION}

Pseudomonas aeruginosa is one of the most important pathogens in the context of CF (2). Infections with $P$. aeruginosa can be distinguished into two different groups: (i). intermittent infections in which the infection with $P$. aeruginosa can be cleared by antipseudomonal treatment, (ii). chronic infections in which $P$. aeruginosa can be isolated from most of the respiratory samples indicating that the respiratory tract is chronically colonized by this bacterium (26). Infections with $P$. aeruginosa are correlated with an accelerated decline in lung function and with an increased incidence of respiratory exacerbations (27, 28). Viral infections have been linked to exacerbations in other chronic pulmonary diseases and respiratory virus infections in CF patients seem to be associated with higher viral burden and higher morbidity (29). Investigation of the link between $P$. aeruginosa and respiratory viruses could therefore identify potential new therapeutic and diagnostic strategies.

We infected human bronchial epithelial cells (BEAS2B and human primary bronchial epithelial cells) with RSV or hRV in the presence of $P$. aeruginosa conditioned medium. We used conditioned medium to analyze soluble, secreted factors from $P$. aeruginosa that might interfere with sensitivity to virus infection. Preliminary experiments (data not shown) indicate that also infection with live $P$. aeruginosa results in inhibition of type III IFN activity and thus recapitulates the effects with conditioned medium. We observed that PAO1 was able to suppress the antiviral response of bronchial epithelial cells toward respiratory viruses (RSV and hRV) which subsequently lead to higher virus titers in secondary infected cells. Due to the stronger effects observed with RSV we subsequently focused on RSV modulation, but findings were similar for hRV (Figures S3-S5). Interestingly, $P$. aeruginosa strain Boston, a control strain frequently used in Pseudomonas research was not able to modulate the antiviral response. Due to genetic heterogeneity, $P$. aeruginosa can be divided into three phylogroups (25). Using representative strains of each group (PAO1-group 1; PA14-group 2; PA7-group 3) we observed that only the minor group 3 strain PA7 was not able to modulate the antiviral response, whereas PA14 could, a clone for which global spread has been shown $(25,30)$. These findings indicate that most of the $P$. aeruginosa strains found in the environment and causing infections in CF patients are able to modulate the antiviral response since most of $P$. aeruginosa isolates are of group 1 or group 2. Two earlier studies could also demonstrate that $P$. aeruginosa is able to modulate the antiviral 

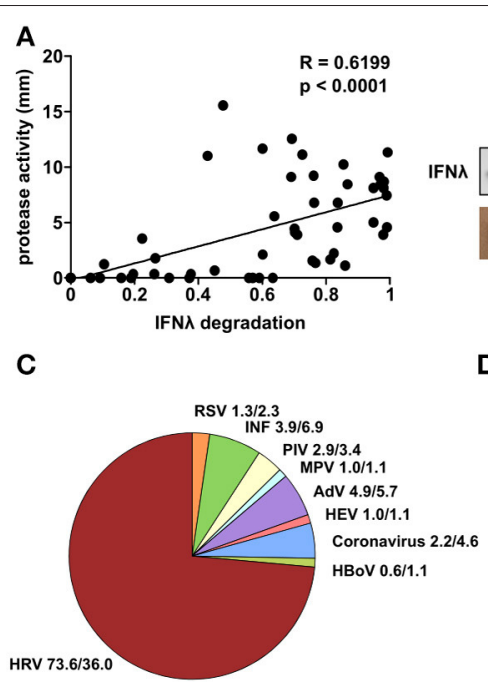

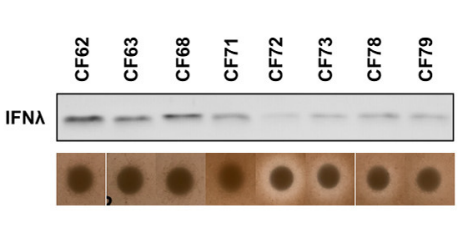

D

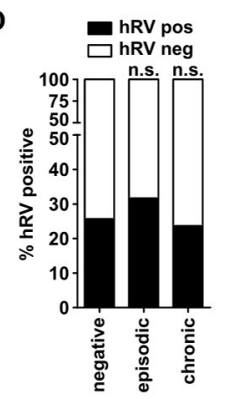

B
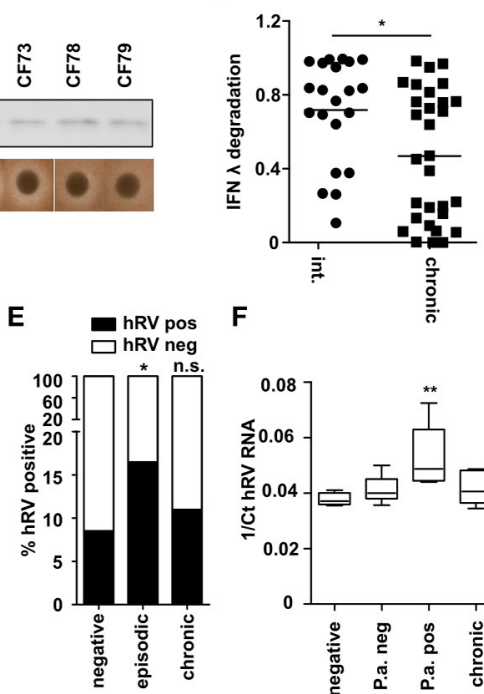

$F$

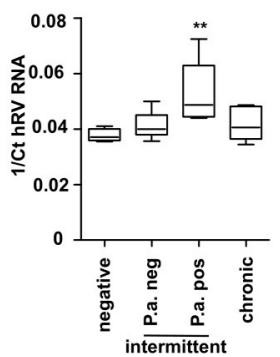

FIGURE 6 | CF patients with intermittent $P$. aeruginosa infection are at higher risk to be infected with hRV. (A) Capacity of CF $P$. aeruginosa isolates to degrade IFN $\lambda$ was analyzed by western blot and protease activity was measured by skim milk agar. Correlation was assessed using Spearman analysis ( $n=51)$. (B) $P$. aeruginosa isolates from (A) were classified according to infection status and plotted against relative IFN $\lambda$ degradation after $1 \mathrm{~h}$. Statistical analysis was done using non-parametric Mann-Whitney test. (C) Presence of respiratory viruses in sputum samples of CF patients were assessed using a multiplex diagnostic virus panel assay. Relative occurrence of respiratory virus positive samples and total samples are indicated $(n=340)$. (D) The prevalence of hRV in CF samples (nose, throat and sputum) was plotted according to the infection status $(n=340)$. Statistics was done by using Fisher's Exact Test. (E) The prevalence of hRV in CF sputum samples was plotted according to the infection status $(n=499)$. Statistics was done by using Fisher's Exact Test. (F) Presence of hRV in sputum from CF patients was assessed by GPCR. The Ct values of hRV was plotted according to the infection status $(n=24)$. Significant differences were considered at ${ }^{\star} p<0.05$, ${ }^{\star \star} p<0.01$, and ${ }^{* \star *} p<0.001$ as compared to the control condition. n.s., not significant.

response of epithelial cells $(31,32)$. In addition, the first study could demonstrate a difference in virus-induced IFN expression between healthy and CF-derived cells. However, we and the second study did not observe differences in IFN induction. In line with our results, a third study also failed to detect a difference of virus-induced IFN production between healthy and CF-derived epithelial cells (33). Therefore, our observations might also be relevant in diseases where chronic $P$. aeruginosa infections occur and a role of respiratory viruses in pulmonary exacerbations has been established, e.g., COPD (34). We have not analyzed whether such modulatory activities are also realized in other lung pathogens, but so far the here identified mechanisms are only reported for $P$. aeruginosa. It has been reported that $P$. aeruginosa PAK1 infection in a mouse model can induce IFN $\lambda$ which promotes an inflammatory response and has a negative impact on $P$. aeruginosa defense in vivo (35). Of note, PAK1 compared to PAO1 has a point mutation in LasR which might affect protease activity (36). Moreover, the PAK strain induced IFN $\beta$ in airway epithelial cells, but CF epithelial cells showed a reduced response compared to healthy cells (37). However, so far it had not been reported that CF epithelial cells display increased sensitivity toward viral infection (38) which was the main focus of our study.

The antiviral response can be subdivided into two stages. First, viruses get recognized by nucleic acid receptors that drive the expression of type I and III interferons. Subsequently, secreted IFN I/III activates the canonical transcription factor STAT1/STAT2/IRF9, which in a positive feedback loop again drives further IFN I/III expression plus additional antiviral genes like OAS1/2 or MX1 (39). Interestingly, the initial induction of IFN $\lambda$ mRNA after virus infection was not altered by PAO1-CM, but nevertheless IFN $\lambda$ protein and signaling was significantly reduced compared to control or Boston-CM treated cells. Of note and in line with the literature, type I IFN was not induced by RSV in bronchial epithelial cells (Figure S2). Further analysis revealed that $P$. aeruginosa secretes proteases degrading type III IFN and thereby inhibiting the antiviral response. Of note, we observed that also exogenous type I IFN was degraded (Figure S6) indicating that in a physiological setting type I IFN as produced by immune cells would also get inactivated. Moreover, protease activity of various $P$. aeruginosa $\mathrm{CF}$ isolates correlated significantly with the ability to degrade recombinant IFN $\lambda$. Most of the secreted proteases are under the control of the quorum sensing regulator LasR and we could demonstrate that the ability of PAO1, Boston or the longitudinal CF isolates to suppress the antiviral response was associated with functional LasR. It is well-known that LasR is subject to mutations in the course of $P$. aeruginosa infections in CF patients e.g., it was reported that in a CF cohort $22 \%$ of the $P$. aeruginosa strains have an altered LasR sequence $(6,25,40,41)$. The involvement of LasR is further supported by the fact that LasR deleted CF $P$. aeruginosa isolates were not able to modulate the 
antiviral response whereas their parental counterpart did. LasR dependent proteases contributing substantially to the virulence of $P$. aeruginosa are AprA, LasA, LasB, and PrpL $(42,43)$. A limitation of the study is that LasR complemented mutants could not be used. However, five independent targeted mutants behave exactly the same way and the loss of the ability to degrade IFN $\lambda$ correlated with a mutated LasR. Using P. aeruginosa PA14 deleted of either of these proteases showed that AprA is mostly responsible for the modulation of the antiviral response. In line with this, comparison of the protein sequence of AprA of PAO1, PA14, and PA7 revealed that PA7/group 3 AprA did not cluster within PA14 or PAO1 (Figure S7). AprA, also known as serralysin or alkaline metalloprotease, is a metalloprotease regulated directly by LasR and has previously been reported to degrade complement, alpha1-proteinase inhibitor, interleukins and interferon gamma $(6,44,45)$. It is secreted as an inactive zymogen, which becomes active by the cleavage of a 9-amino acid propeptide either by other proteases (LasA/B) or in an autocatalytic manner. To our knowledge this is the first study showing that AprA is also able to degrade IFN $\lambda$ thereby modulating the antiviral response of epithelial cells. It is wellknown that $\mathrm{CF}$ patients produce antibodies against several Pseudomonas antigens including AprA. Moreover, it has been shown that these antibodies are able to block AprA activity (4649). These antibodies would therefore be able to counteract AprA dependent type III IFN degradation. However, these antibodies need to be present at high titers at the site of infection in the conducting airways. Since high titers are regularly detected only in chronically infected patients neutralizing antibodies are only present when AprA expression is decreased. In addition, anti AprA antibodies are IgG subtypes which get passively secreted in the alveolar space and subsequently transported by the mucocilliary escalator to the airways $(50,51)$. Considering decreased mucocilliary clearance in CF patients sufficient titers might not be reached in this condition. In line with our results, Bomberger et al. were able to show that CFTR inhibitory factor (CIF), secreted by $P$. aeruginosa, is able to block presentation of viral antigens on MHC class I of bronchial epithelial cells and recognition by $\mathrm{CD}^{+}$cells adding another layer of complexity on how P. aeruginosa is able to modulate the antiviral defense (52).

Chronic infection with $P$. aeruginosa in CF is subject to a complex adaptation to the CF lung leading to increased biofilm production and a decrease in the expression of various virulence factors, including secreted proteases $(26,53)$. In line with this, total protease activity of $P$. aeruginosa isolates derived from $\mathrm{CF}$ patients correlated with their potential to degrade IFN $\lambda$ and, interestingly, the ability to degrade IFN $\lambda$ was associated with intermittent infection status. At closer analysis, the capacity of IFN $\lambda$ degradation of $P$. aeruginosa isolated from chronically infected patients clustered into two groups. Several reasons can be accounted for this observation. First, staging of patients into chronic or intermittent can be challenging for the clinician and is sometimes not entirely correct. Therefore, scientists search for additional biomarkers of chronicity because treatment of the patients is based on this classification (54). Moreover, CF patients could be colonized by several $P$. aeruginosa strains which do not always display the same phenotype $(26,53)$. Nevertheless, median IFN degradation activity was significantly decreased in chronic patients, therefore we conclude that chronic patients might have a lower risk of virus infection compared to intermittently infected patients. As discussed before, chronic patients have higher anti-AprA in the serum and this together with decreased protease activity might account for the lower infection rate seen in infected patients.

In order to further investigate a potential link between respiratory viruses and $P$. aeruginosa infections, we screened respiratory material of CF patients using a multiplex PCR based assay. In line with a similar study, we could detect mainly human rhinovirus and to a much lesser extent RSV, Influenza-A/B, Adenovirus or Parainfluenza Virus $(55,56)$. Interestingly, CF patients intermittent infected with $P$. aeruginosa had a higher risk for hRV infection (Odds ratio $=2.374$ ) and displayed higher virus loads in the sputum compared to $P$. aeruginosa negative or chronically infected patients. However, this observation could just be made if material of the lower respiratory tract (sputum) was analyzed. If also samples from the upper airways (nose, throat) were considered no statistical difference between all groups could be seen. Considering that hRV normally infects the upper respiratory tract, increased detection rates in the lower respiratory airways in $P$. aeruginosa positive individuals might be an indicator for a higher disease burden of hRV infection, similar to the situation in asthmatic or COPD patients (20).

Pseudomonas aeruginosa infections have been associated with a worse outcome in $\mathrm{CF}$ and with an increased exacerbation rate $(10,57)$. Interestingly pulmonary exacerbation in CF has been associated with respiratory viruses $(13,14,20,55)$, which might indicate an interplay between respiratory viruses and $P$. aeruginosa infections. This might be more important at early stages of CF when P. aeruginosa infections are not yet chronic. In addition, respiratory virus infections have been associated with the conversion of intermittent infections to chronic infections with $P$. aeruginosa $(22,23)$ caused by increased biofilm growth of $P$. aeruginosa due to increased iron concentrations in the lung (58). Thereby $P$. aeruginosa would directly benefit from a viral infection. Bacterial superinfections of respiratory viral infections are much better described in the literature than viral superinfections and involvement of interferon $\lambda$ in this scenario has been suggested as well (59). However, several studies show that gut bacteria are able to foster enteric virus infections $(60,61)$ even though the underlying mechanisms are different $(62,63)$. In addition, AprA or another LasR dependent protease might directly modify RSV or hRV virions thereby increasing their infectivity, similar to reoviruses (64).

Taken together we could show that $P$. aeruginosa is able to suppress the antiviral response of bronchial epithelial cells by the direct degradation of IFN $\lambda$. This degradation was dependent on the quorum sensing transcription factor LasR and the protease AprA. In addition, the infection status of CF patients was associated with the potential to degrade IFN $\lambda$ and with presence of respiratory viruses in sputum. Therefore, we conclude that interfering with the antiviral response might lead to an increased 
susceptibility of $P$. aeruginosa infected CF patients for respiratory viruses causing respiratory exacerbations or foster the conversion of intermittent to chronic $P$. aeruginosa infections.

\section{MATERIALS AND METHODS}

\section{Materials}

RPMI 1640 medium was purchased from Biochrom (Berlin, Germany). FCS was from Life Technologies (Carlsbad, CA, USA). Penicillin and streptomycin were from PAA Laboratories (Pasching, Austria). PBS was obtained from PAN-Biotech (Aidenbach, Germany). EBSS was from Sigma-Aldrich (Saint Louis, MO, USA). Bronchial epithelial basal medium (BEBM) and supplementary growth factors were all from Lonza (Walkersville, MD, USA). PureCol (type I bovine collagen solution, $3 \mathrm{mg} / \mathrm{ml}$ ) was from Advanced BioMatrix (San Diego, CA, USA). Soybean trypsin inhibitor (STI), DNase I, and Protease XIV were from Sigma-Aldrich. Primary antibodies detecting pSTAT1 and actin were all from Cell Signaling Biotechnology (Frankfurt, Germany). IFN $\lambda$ antibody was from abcam (ab38569, Cambridge, UK).

\section{Cell Culture}

Human bronchial epithelial BEAS-2B cells were cultured in RPMI growth medium, supplemented with $10 \%$ FCS, $1 \%$ penicillin/streptomycin at $37^{\circ} \mathrm{C}$ in a humidified incubator at $5 \%$ $\mathrm{CO}_{2}$. Human primary bronchial epithelial cell cultures (primary HBE) were bought from Lonza (Visp, Switzerland) or isolated from biopsies from individuals treated by lobectomy because of non-small-cell lung carcinoma at the Thoraxklinik Heidelberg. Ethics approval (S-381/2014) was obtained from the regional Ethics Committee at the University of Heidelberg, and all study participants provided a written informed consent. Two methods of bronchial epithelial cells isolation were used $(65,66)$ : Briefly, the obtained biopsies were washed with cold EBSS and cleaned from any additional connective tissue and mucus. The segments were then cut open and incubated on a shaker at $4{ }^{\circ} \mathrm{C}$ overnight in $9 \mathrm{ml}$ EBSS including $1 \mathrm{ml}$ digestion solution (DS, 10x: $0.01 \%$ DNase I, $1 \%$ Protease XIV in sterile PBS). On the next day, $1.1 \mathrm{ml} \mathrm{FCS}$ was added to the solution to terminate digestion. The epithelium was scraped into the digestion medium using a sterile scalpel. The biopsies were additionally washed with EBSS. All epithelial cells from scraping were collected by spinning at $4{ }^{\circ} \mathrm{C}$ at $500 \times \mathrm{g}$ for $5 \mathrm{~min}$. Cell pellets were resuspended in $10 \mathrm{ml}$ of warm BEGM (Lonza) and cells were then seeded into collagen-coated ( 3 $\mathrm{mg} / \mathrm{ml}$ PureCol, Cellsystems, 1:75 in $\mathrm{ddH}_{2} \mathrm{O}$ ) prewarmed $10 \mathrm{~cm}$ culture dishes.

Additionally, isolation using an outgrowth method was performed: Bronchial segments were cut into $2-3 \mathrm{~mm}^{3}$ pieces and placed into collagen-coated 6-well-plates. These pieces served as a source of primary cells and grown out epithelial cells were transferred into collagen-coated $10 \mathrm{~cm}$ dishes as soon as they reached $70 \%$ confluence. Primary cell cultures were maintained at $37^{\circ} \mathrm{C}$ in a humidified incubator at $5 \% \mathrm{CO}_{2}$. Culture medium (BEBM + Supplements) was changed every 23 days. Cells were passaged when reaching $70-90 \%$ confluency. After 2 washes with PBS, they were trypsinized with $2 \mathrm{ml}$ of
$0.05 \%$ trypsin/EDTA and incubated $5-10 \mathrm{~min}$ at $37^{\circ} \mathrm{C}$. Cells were then rinsed twice with PBS, harvested and pooled into a tube containing soybean trypsin inhibitor (STI, $1 \mathrm{mg} / \mathrm{ml}$ ) on ice. After spinning at $500 \times \mathrm{g}$ for $5 \mathrm{~min}$, the pellets were resuspended in $10 \mathrm{ml}$ BEGM and cell suspension was split into two new collagen-coated $10 \mathrm{~cm}$ dishes.

\section{$P$. aeruginosa Strains and Virus Infections}

Various $P$. aeruginosa strains (Table $\mathbf{1}$ ) were cultured in lysogeny broth (LB) broth overnight at $37^{\circ} \mathrm{C}$, shaking at $200 \mathrm{rpm}$. The culture was then diluted 1:50 in RPMI-1640 medium and grown for 5 days at $37^{\circ} \mathrm{C}$, shaking at $200 \mathrm{rpm}$, in order to activate quorum-sensing and virulence factor secretion. On day 5 , the medium was centrifuged for $10 \mathrm{~min}$ at 4,200 $\mathrm{rcf}$ and passed through a $0.2 \mu \mathrm{m}$ filter. This medium was used as conditioned medium (CM). For each experiment at least two different $\mathrm{CM}$ were used. A RPMI-1640 control was cultured and filtered alongside the cultured $P$. aeruginosa strains. 100,000 BEAS2B or primary cells were seeded in 24-well-plates in BEAS2B medium. The following day, the cell medium was changed to infection medium, which was RPMI-1640 supplemented with $2 \%$ FCS, $1 \%$ $\mathrm{P} / \mathrm{S}, 25 \mathrm{mM}$ HEPES, and $0.075 \% \mathrm{NaHCO}_{3}$. Twenty-four hours later, BEAS2B were pretreated with CM $(20 \% \mathrm{v} / \mathrm{v})$ for $1 \mathrm{~h}$ at $37^{\circ} \mathrm{C}, 5 \% \mathrm{CO}_{2}$. Cell medium was then removed, and respiratory syncytial virus (RSV) or rhinovirus (RV1B) at a multiplicity of infection of 1 (MOI 1) (stocks prepared in house) in combination with fresh CM was added to BEAS2B cells. After $1 \mathrm{~h}$ at room temperature, shaking at $30 \mathrm{rpm}$, medium was removed, cells washed twice with warm $1 \mathrm{X}$ PBS, and infection medium added to the cells. Fresh CM was once again added to the cells as indicated above. Cell culture supernatant was collected at the indicated times and cells were lysed in RNA lysis buffer.

\section{Western Blotting}

BEAS2B cells were stimulated as indicated, subsequently washed with PBS, and lysed in Laemmli buffer [ $400 \mathrm{mM}$ Tris- $\mathrm{HCl}$, $\mathrm{pH}$ 6.8, 20\% (v/v) $\beta$-mercaptoethanol, 40\% (v/v) glycerol, $8 \%$ $(\mathrm{w} / \mathrm{v}) \mathrm{SDS}$, and $0.4 \%(\mathrm{v} / \mathrm{v})$ bromophenol blue]. After incubation for $10 \mathrm{~min}$ at $98^{\circ} \mathrm{C}$, equal amounts of lysates were fractionated by $10 \%$ polyacrylamide gel (SDS-PAGE) and electrotransferred to Nitrocellulose membranes by a semidry blotting procedure [buffer: $25 \mathrm{mM}$ Tris, $192 \mathrm{mM}$ Glycin, 10\% (v/v) methanol; 2.5 $\mathrm{mA} / \mathrm{cm}^{2}$ for $1 \mathrm{~h} 15 \mathrm{~min}$ ]. Blocking of unspecific binding was performed using $5 \%$ BSA solution in $1 \times$ TBST [ $1 \times$ TBS, $0.05 \%$ $(\mathrm{v} / \mathrm{v})$ Tween-20] for at least $1 \mathrm{~h}$. Membranes were stained with antibodies against pY-STAT1 (Tyr701, \#9167), STAT1 (\#9172), $\beta$-Actin (\#4970) (Cell Signaling, Leiden, Netherlands; 1:1,000) overnight at $4^{\circ} \mathrm{C}$. After three $10 \mathrm{~min}$ washing steps in $1 \times$ TBST at room temperature, blots were incubated with secondary antibodies for $1 \mathrm{~h}$ at RT [HRP-linked anti-mouse or anti-rabbit (Cell Signaling, Leiden, Netherlands)], followed by additional three 10 min washing steps in $1 \times$ TBST at room temperature. Proteins were detected using an enhanced chemiluminescence system (Western lightning ${ }^{\mathrm{TM}}$ plus ECL, Perkin-Elmer, Rodgau, Germany). Gels were imaged digitally, and contrast adjustments were applied to all parts of a figure. The prestained molecular weight marker was imaged separately (using transmitted light) 
TABLE 1 | Strain descriptions.

\begin{tabular}{|c|c|c|c|}
\hline No. & Strain & $\begin{array}{l}\text { Description and } \\
\text { characteristics }\end{array}$ & References \\
\hline 1 & PAO1 & $\begin{array}{l}\text { Pseudomonas aeruginosa } \\
\text { wild type }\end{array}$ & DSMZ 22644 \\
\hline 2 & Boston & $\begin{array}{l}\text { Pseudomonas aeruginosa } \\
\text { wild type }\end{array}$ & ATCC 27853 \\
\hline 3 & PA14 & $\begin{array}{l}\text { Pseudomonas aeruginosa } \\
\text { wild type }\end{array}$ & DSMZ 19882 \\
\hline 4 & PA7 & $\begin{array}{l}\text { Pseudomonas aeruginosa } \\
\text { wild type }\end{array}$ & DSMZ 24068 \\
\hline 5 & CF1.1 & CF patient isolate & $(6,40)$ \\
\hline 6 & CF1.2 & $\begin{array}{l}\text { CF patient isolate, clonally } \\
\text { related to } 5\end{array}$ & $(6,40)$ \\
\hline 7 & CF2.1 & CF patient isolate & $(6,40)$ \\
\hline 8 & CF2.2 & $\begin{array}{l}\text { CF patient isolate, clonally } \\
\text { related to } 7\end{array}$ & $(6,40)$ \\
\hline 9 & CF3.1 & CF patient isolate & $(6,40)$ \\
\hline 10 & CF3.2 & $\begin{array}{l}\text { CF patient isolate, clonally } \\
\text { related to } 9\end{array}$ & $(6,40)$ \\
\hline 11 & CF4.1 & CF patient isolate & $(6,40)$ \\
\hline 12 & CF4.2 & $\begin{array}{l}\text { CF patient isolate, clonally } \\
\text { related to } 11\end{array}$ & $(6,40)$ \\
\hline 13 & CF1 & CF patient isolate & $(6,40)$ \\
\hline 14 & $\mathrm{CF} 1 \Delta \mathrm{lasR}$ & CF1 lasR deletion mutant & $(6,40)$ \\
\hline 15 & CF2 & CF patient isolate & $(6,40)$ \\
\hline 16 & $\mathrm{CF} 2 \Delta \mathrm{lasR}$ & CF2 lasR deletion mutant & $(6,40)$ \\
\hline 17 & CF3 & CF patient isolate & $(6,40)$ \\
\hline 18 & CF3 $\Delta$ lasR & CF3 lasR deletion mutant & $(6,40)$ \\
\hline 19 & CF4 & CF patient isolate & $(6,40)$ \\
\hline 20 & CF4 4 lasR & CF4 lasR deletion mutant & $(6,40)$ \\
\hline 21 & CF5 & CF patient isolate & $(6,40)$ \\
\hline 22 & CF5 $\Delta$ lasR & CF5 lasR deletion mutant & $(6,40)$ \\
\hline 23 & PA14 & $\begin{array}{l}\text { Pseudomonas aeruginosa } \\
\text { wild type parental strain of } \\
24,25,26,27\end{array}$ & $(43,67)$ \\
\hline 24 & PA14 $\triangle$ AprA & $\begin{array}{l}\text { PA14 transposon insertion } \\
\text { mutant, ID23768 }\end{array}$ & $(43,68)$ \\
\hline 25 & PA14 $\Delta$ LasA & $\begin{array}{l}\text { PA14 transposon insertion } \\
\text { mutant, ID35267 }\end{array}$ & $(43,68)$ \\
\hline 26 & $\mathrm{PA} 14 \Delta \mathrm{LasB}$ & $\begin{array}{l}\text { PA14 transposon insertion } \\
\text { mutant, ID31938 }\end{array}$ & $(43,68)$ \\
\hline 27 & PA14 4 PrpL & $\begin{array}{l}\text { PA14 transposon insertion } \\
\text { mutant, ID37740 }\end{array}$ & $(43,68)$ \\
\hline
\end{tabular}

and aligned to the digital images of the blots. The ladder is represented on the blots as black bars. Where indicated, membranes were stripped and reprobed. Densitometry was performed using ImageJ software (National Institutes of Health).

\section{RNA Isolation and Quantitative RT-PCR}

Total cellular RNA was isolated using peqGold Total RNA Kit (peqlab Biotechnology, Erlangen, Germany) according to the manufacturer's standard protocol. RNA isolation included DNase digestion using an RNase-free DNase set (Qiagen, Hilden, Germany). In order to perform quantitative RT-PCR, total RNA
TABLE 2 | Primer sequences.

\begin{tabular}{|c|c|c|}
\hline Name & Direction & Sequence \\
\hline \multirow[t]{2}{*}{$M \times 1$} & Fw & CTGCACAGGTTGTTCTCAGC \\
\hline & Rev & CCAAGGTCCACCGTGATTAAC \\
\hline \multirow[t]{2}{*}{ OAS1 } & $\mathrm{FW}$ & TGTCCAAGGTGGTAAAGGGTG \\
\hline & Rev & CCGGCGATITAACTGATCCTG \\
\hline \multirow[t]{2}{*}{$R v 1 b$} & $\mathrm{FW}$ & CTAGCCTGCGTGG \\
\hline & Rev & AAACACGGACACCCAAAGT \\
\hline \multirow[t]{2}{*}{ RSV } & $\mathrm{FW}$ & GATATGCCTATAACAAAT \\
\hline & Rev & GATACTGATCCTGCATT \\
\hline \multirow[t]{2}{*}{ hIFNa1 } & $\mathrm{FW}$ & CAGAGTCACCCATCTCAGCA \\
\hline & Rev & CACCACCAGGACCATCAG \\
\hline \multirow[t]{2}{*}{ hIFNa2 } & $\mathrm{FW}$ & CTGGCACAAATGGGAAGAAT \\
\hline & Rev & CTTGAGCCTTCTGGAACTGG \\
\hline \multirow[t]{2}{*}{ hIFNb } & Fw & CGCCGCATTGACCATCTA \\
\hline & Rev & GACATTAGCCAGGAGGTTCTCA \\
\hline \multirow[t]{2}{*}{ hIFNL1 } & $\mathrm{FW}$ & GGACGCCTTGGAAGAGTCACT \\
\hline & Rev & AGAAGCCTCAGGTCCCAATTC \\
\hline \multirow[t]{2}{*}{ hIFNL2/3 } & $\mathrm{FW}$ & CTGCCACATAGCCCAGTTCA \\
\hline & Rev & AGAAGCGACTCTTCTAAGGCATCTT \\
\hline
\end{tabular}

was first reverse transcribed into single stranded cDNA using High Capacity cDNA RT Kit (Applied Biosystems, Foster City, CA). For RT-PCR analysis, $2 \mu \mathrm{l}$ of cDNA (diluted 1:4) was used as a template in a final reaction volume of $15 \mu \mathrm{l}$, combined with SYBR $^{\circledR}$ Green PCR Master Mix Fast (Applied Biosystems) and corresponding primers (Table 2). The analysis was performed on a StepOne Plus RT-PCR platform (Applied Biosystems) in 96-well-format. Each gene was measured in duplicates of each cDNA sample. The baseline and threshold values were detected automatically and the $\mathrm{Ct}$ values of the endogenous constitutively expressed reference gene (ACTB) were subtracted from the determined $\mathrm{Ct}$ values resulting in a $-\Delta \mathrm{Ct}$ for each target gene, which was then used to calculate the relative expression, $\mathrm{rE}=2^{-\Delta C t}$. To control reaction specificity, all measurements included samples without the reverse transcriptase enzyme (noRT). Melting curves were used to prove specific amplification. Fold induction was calculated of the ratio of $\mathrm{rE}_{\text {treated }} / \mathrm{rE}_{\mathrm{Ctr}}$.

\section{Measurement of Cytokine Secretion}

Sandwich enzyme-linked immunosorbent assay (ELISA) was performed using commercially available kits (eBioscience, human IL29 ELISA) to determine the amount of secreted human IFN $\lambda$ in the cell-free supernatants of stimulated cells. Samples were tested in duplicates and the assays were performed according to the manufacturers' instructions. Cytokines were detected by measuring the absorbance at $490 \mathrm{~nm}$ with a 650 $\mathrm{nm}$ reference in a photometer (Sunrise reader, Tecan, Salzburg, Austria). Cytokine concentrations were calculated according to a standard dilution of the respective recombinant cytokines using Magellan V 5.0 software (Tecan, Salzburg, Austria).

\section{Protease Activity Assay, Zymography}

$\mathrm{CM}$ was treated with non-reducing Western blot sample buffer and separated by SDS-PAGE (10\% polyacrylamide gel containing 
$0.1 \%$ gelatin). The gels were washed twice with $2.5 \%$ Triton$\mathrm{X}-100$ for $15 \mathrm{~min}$ followed by an overnight incubation at $37^{\circ} \mathrm{C}$ in substrate buffer $\left(10 \mathrm{mM}\right.$ Tris, $\mathrm{pH} 8.0,10 \mathrm{mM} \mathrm{CaCl}_{2}, 1 \mu \mathrm{M}$ $\mathrm{ZnCl}, 150 \mathrm{mM} \mathrm{NaCl})$. Subsequently the gel was stained with 0.5\% Coomassie blue in acetic acid:isopropanol: $\mathrm{dH}_{2} \mathrm{O}(10: 30: 60)$ and pictures were taken after destaining with $\mathrm{dH}_{2} \mathrm{O}$. In order to determine total protease activity in CM a sterile $6 \mathrm{~mm}$ filter disk was added on skim milk agar (1.5\%) and $10 \mu \mathrm{l}$ of CM was added. Following incubation at $37^{\circ} \mathrm{C}$ the diameter of clearance (as an indication of protease activity) was measured.

\section{In vitro Degradation of IFN $\lambda$}

IFN $\lambda$ was incubated with $\mathrm{CM}$ for the indicated time at $37^{\circ} \mathrm{C}$ and $5 \% \mathrm{CO}_{2}$ in the dark. As a loading control IFN $\lambda$ was added to RPMI only. Reactions were stopped by adding western blot sample buffer and heat treatment $\left(95^{\circ} \mathrm{C}, 10 \mathrm{~min}\right)$. Subsequently samples were used for western blot analysis. Quantification was performed using ImageJ and samples were normalized to the input control.

\section{Patients and Virus Detection}

Studies including samples from CF patients were approved by the Ethics Committee of the University of Heidelberg (study number S-370/2011). Informed written consent was obtained from the patients, parents, or legal guardians of all subjects. Airway samples from CF patients (sputum, throat swab) were obtained during routine visits at the CF Center at the University Hospital Heidelberg as previously described (54). The diagnosis of CF was based on established diagnostic criteria. Samples were used for isolation of $P$. aeruginosa strains $(n=51)$ and sputum, nose or throat swabs were analyzed for virus infection by multiplex PCR (Seegene, Korea, Allplex ${ }^{\mathrm{TM}}$ respiratory panels 1-4) or by targeted RT-PCR after RNA extraction using TRIZOL and cDNA synthesis as described above. Infection status with $P$. aeruginosa (intermittent or chronic) was classified according to the following definition (69): Intermittent infection was defined as positive microbial culture of $P$. aeruginosa in at least one and $<50 \%$ of the samples in the last 12 months and no detection of anti-Pseudomonas antibodies (against alkaline protease, elastase, and exotoxin A). Chronic infection was defined as persistent culture presence of $P$. aeruginosa for at least 6 months, or less when combined with a positive finding (titer $>1,250$ ) of two or more antibodies.

\section{Statistical Analysis}

All experiments were repeated three times unless stated otherwise. Data are shown as mean + SD. Statistical significance of comparison between three or more unmatched groups was determined by one-way ANOVA and if multiple comparisons were performed, two-way ANOVA was used (both including Bonferroni post-test). Statistics on quantitative PCR (qPCR) data were performed on previously log-transformed data to achieve a normal distribution. All statistical analyses were done using GraphPad Prism (GraphPad 5.00 and 6.05, San Diego, USA) software. Significant differences were considered at $* p<0.05$, ${ }^{* *} p<0.01$, and ${ }^{* * *} p<0.001$ as compared to the control condition. n.s., not significant.

\section{DATA AVAILABILITY STATEMENT}

All datasets generated for this study are included in the article/Supplementary Material.

\section{ETHICS STATEMENT}

The studies involving human participants were reviewed and approved by the Ethics Committee of the University of Heidelberg. The patients/participants provided their written informed consent to participate in this study.

\section{AUTHOR CONTRIBUTIONS}

MS and $\mathrm{AD}$ conceived and designed the experiments. MS, JK, and LB performed the experiments. SB and MS analyzed the data. FL, HZ, and DN provided study material. MS, AD, MM, and DN conceptualized the study. MS and AD wrote the paper.

\section{FUNDING}

This study was supported in part by the German Ministry for Education and Research (82DZL00401 and 82DZL004A1) and by the German Research Foundation (DFG Da592/6-1).

\section{ACKNOWLEDGMENTS}

We acknowledge the excellent work and technical support of Selina Tümkaja, Suzan Leccese, Selina Hassel, and Lan-Sun Chen.

\section{SUPPLEMENTARY MATERIAL}

The Supplementary Material for this article can be found online at: https://www.frontiersin.org/articles/10.3389/fimmu. 2020.00096/full\#supplementary-material

\section{REFERENCES}

\footnotetext{
1. Elborn

(2016)

\begin{abstract}
JS. Cystic
\end{abstract}
388:2519-31.

fibrosis.

Lancet

10.1016

00576-6

2. CFF Patient Registry Annual Data Report - 2015-Patient-Registry-AnnualData-Report. Available online at: https://www.cff.org/Our-Research/CFPatient-Registry/2015-Patient-Registry-Annual-Data-Report.pdf (accessed February 27, 2017).
}

3. Nixon GM, Armstrong DS, Carzino R, Carlin JB, Olinsky A, Robertson CF, et al. Clinical outcome after early Pseudomonas aeruginosa infection in cystic fibrosis. J Pediatr. (2001) 138:699-704. doi: 10.1067/mpd.2001.112897

4. Emerson J, Rosenfeld M, McNamara S, Ramsey B, Gibson RL. Pseudomonas aeruginosa and other predictors of mortality and morbidity in young children with cystic fibrosis. Pediatr Pulmonol. (2002) 34:91-100. doi: 10.1002/ppul.10127

5. Döring G, Conway SP, Heijerman HG, Hodson ME, Høiby N, Smyth A, et al. Antibiotic therapy against Pseudomonas aeruginosa in cystic 
fibrosis: a European consensus. Eur Respir J. (2000) 16:749-67. doi: 10.1034/j.1399-3003.2000.16d30.x

6. LaFayette SL, Houle D, Beaudoin T, Wojewodka G, Radzioch D, Hoffman LR, et al. Cystic fibrosis-adapted Pseudomonas aeruginosa quorum sensing lasR mutants cause hyperinflammatory responses. Sci Adv. (2015) 1:e1500199. doi: 10.1126/sciadv.1500199

7. Galdino ACM, Branquinha MH, Santos ALS, Viganor L. Pseudomonas aeruginosa and Its arsenal of proteases: weapons to battle the host. In: Chakraborty. S, Dhalla N. S., editors. Pathophysiological Aspects of Proteases. Singapore: Springer (2017).p. 381-97. doi: 10.1007/978-981-10-6141-7_16

8. Bardoel BW, van Kessel KPM, van Strijp JAG, Milder FJ. Inhibition of Pseudomonas aeruginosa virulence: characterization of the AprAAprI interface and species selectivity. J Mol Biol. (2012) 415:57383. doi: 10.1016/j.jmb.2011.11.039

9. Laarman AJ, Bardoel BW, Ruyken M, Fernie J, Milder FJ, van Strijp JA, et al. Pseudomonas aeruginosa alkaline protease blocks complement activation via the classical and lectin pathways. J Immunol. (2012) 188:38693. doi: 10.4049/jimmunol.1102162

10. Goss CH, Burns JL. Exacerbations in cystic fibrosis. 1: epidemiology and pathogenesis. Thorax. (2007) 62:360-7. doi: 10.1136/thx.2006.060889

11. Waters V, Ratjen F. Pulmonary exacerbations in children with cystic fibrosis. Ann Am Thorac Soc. (2015) 12(Suppl. 2):S2006. doi: 10.1513/AnnalsATS.201502-098AW

12. Kurai $D$, Saraya T, Ishii $H$, Takizawa H. Virus-induced exacerbations in asthma and COPD. Front Microbiol. (2013) 4:293. doi: 10.3389/fmicb.2013.00293

13. Ortiz JR, Neuzil KM, Victor JC, Wald A, Aitken ML, Goss CH. Influenzaassociated cystic fibrosis pulmonary exacerbations. Chest. (2010) 137:85260. doi: 10.1378/chest.09-1374

14. Wang EE, Prober CG, Manson B, Corey M, Levison H. Association of respiratory viral infections with pulmonary deterioration in patients with cystic fibrosis. N Engl J Med. (1984) 311:16538. doi: 10.1056/NEJM198412273112602

15. Cuthbertson L, Rogers GB, Walker AW, Oliver A, Green LE, Daniels TWV, et al. Respiratory microbiota resistance and resilience to pulmonary exacerbation and subsequent antimicrobial intervention. ISME J. (2016) 10:1081-91. doi: 10.1038/ismej.2015.198

16. Carmody LA, Zhao J, Schloss PD, Petrosino JF, Murray S, Young VB, et al. Changes in cystic fibrosis airway microbiota at pulmonary exacerbation. Ann Am Thorac Soc. (2013) 10:179-87. doi: 10.1513/AnnalsATS.201211-107OC

17. Odendall C, Kagan JC. The unique regulation and functions of type III interferons in antiviral immunity. Curr Opin Virol. (2015) 12:4752. doi: 10.1016/j.coviro.2015.02.003

18. Andreakos E, Salagianni M, Galani IE, Koltsida O. Interferon- $\lambda$ s: Front-Line Guardians of Immunity and Homeostasis in the Respiratory Tract. Front Immunol. (2017) 8:1232. doi: 10.3389/fimmu.2017.01232

19. Lazear HM, Nice TJ, Diamond MS. Interferon- $\lambda$ : Immune functions at barrier surfaces and beyond. Immunity. (2015) 43:15-28. doi: 10.1016/j.immuni.2015.07.001

20. Ritchie AI, Farne HA, Singanayagam A, Jackson DJ, Mallia P, Johnston SL. Pathogenesis of viral infection in exacerbations of airway disease. Ann Am Thorac Soc. (2015) 12(Suppl. 2):S115-32. doi: 10.1513/AnnalsATS.201503-151AW

21. Edwards MR, Regamey N, Vareille M, Kieninger E, Gupta A, Shoemark A, et al. Impaired innate interferon induction in severe therapy resistant atopic asthmatic children. Mucosal Immunol. (2013) 6:797-806. doi: 10.1038/mi.2012.118

22. Johansen HK, Høiby N. Seasonal onset of initial colonisation and chronic infection with Pseudomonas aeruginosa in patients with cystic fibrosis in Denmark. Thorax. (1992) 47:109-11. doi: 10.1136/thx.47.2.109

23. Esther CR, Lin F-C, Kerr A, Miller MB, Gilligan PH. Respiratory viruses are associated with common respiratory pathogens in cystic fibrosis. Pediatr Pulmonol. (2014) 49:926-31. doi: 10.1002/ppul.22917

24. Worlitzsch D, Tarran R, Ulrich M, Schwab U, Cekici A, Meyer KC, et al. Effects of reduced mucus oxygen concentration in airway Pseudomonas infections of cystic fibrosis patients. J Clin Invest. (2002) 109:31725. doi: $10.1172 /$ JCI0213870

25. Freschi L, Jeukens J, Kukavica-Ibrulj I, Boyle B, Dupont M-J, Laroche J, et al. Clinical utilization of genomics data produced by the international Pseudomonas aeruginosa consortium. Front Microbiol. (2015) 6:1036. doi: $10.3389 /$ fmicb.2015.01036

26. Winstanley C, O'Brien S, Brockhurst MA. Pseudomonas aeruginosa evolutionary adaptation and diversification in cystic fibrosis chronic lung infections. Trends Microbiol. (2016) 24:327-37. doi: 10.1016/j.tim.2016. 01.008

27. Li Z, Kosorok MR, Farrell PM, Laxova A, West SEH, Green CG, et al. Longitudinal development of mucoid Pseudomonas aeruginosa infection and lung disease progression in children with cystic fibrosis. JAMA. (2005) 293:581-8. doi: 10.1001/jama.293.5.581

28. Sanders DB, Fink AK. Background and epidemiology. Pediatr Clin North Am. (2016) 63:567-84. doi: 10.1016/j.pcl.2016.04.001

29. Kieninger E, Singer F, Tapparel C, Alves MP, Latzin P, Tan H-L, et al. High rhinovirus burden in lower airways of children with cystic fibrosis. Chest. (2013) 143:782-90. doi: 10.1378/chest.12-0954

30. Fothergill JL, Walshaw MJ, Winstanley C. Transmissible strains of Pseudomonas aeruginosa in cystic fibrosis lung infections. Eur Respir J. (2012) 40:227-38. doi: 10.1183/09031936.00204411

31. Chattoraj SS, Ganesan S, Faris A, Comstock A, Lee W-M, Sajjan US. Pseudomonas aeruginosa suppresses interferon response to rhinovirus infection in cystic fibrosis but not in normal bronchial epithelial cells? Infect Immun. (2011) 79:413145. doi: 10.1128/IAI.05120-11

32. Dauletbaev N, Das M, Cammisano $M$, Chen H, Singh S, Kooi C, et al. Rhinovirus load is high despite preserved interferon- $\beta$ response in cystic fibrosis bronchial epithelial cells. PLoS ONE. (2015) 10:e0143129. doi: 10.1371/journal.pone.0143129

33. Vareille M, Kieninger E, Alves MP, Kopf BS, Möller A, Geiser T, et al. Impaired type I and type III interferon induction and rhinovirus control in human cystic fibrosis airway epithelial cells. Thorax. (2012) 67:51725. doi: 10.1136/thoraxjnl-2011-200405

34. Martínez-Solano L, Macia MD, Fajardo A, Oliver A, Martinez JL. Chronic Pseudomonas aeruginosa infection in chronic obstructive pulmonary disease. Clin Infect Dis. (2008) 47:1526-33. doi: 10.1086/593186

35. Cohen TS, Prince AS. Bacterial pathogens activate a common inflammatory pathway through IFN $\lambda$ regulation of PDCD4. PLoS Pathog. (2013) 9:e1003682. doi: 10.1371/journal.ppat.1003682

36. Winsor GL, Griffiths EJ, Lo R, Dhillon BK, Shay JA, Brinkman FSL. Enhanced annotations and features for comparing thousands of Pseudomonas genomes in the Pseudomonas genome database. Nucleic Acids Res. (2016) 44:D64653. doi: 10.1093/nar/gkv1227

37. Parker D, Cohen TS, Alhede M, Harfenist BS, Martin FJ, Prince A. Induction of type I interferon signaling by Pseudomonas aeruginosa is diminished in cystic fibrosis epithelial cells. Am J Respir Cell Mol Biol. (2012) 46:613. doi: $10.1165 / \mathrm{rcmb} .2011-00800 \mathrm{C}$

38. Schögler A, Stokes AB, Casaulta C, Regamey N, Edwards MR, Johnston $\mathrm{SL}$, et al. Interferon response of the cystic fibrosis bronchial epithelium to major and minor group rhinovirus infection. J Cyst Fibros. (2016) 15:3329. doi: 10.1016/j.jcf.2015.10.013

39. McNab F, Mayer-Barber K, Sher A, Wack A, O'Garra A. Type I interferons in infectious disease. Nat Rev Immunol. (2015) 15:87-103. doi: 10.1038/ nri3787

40. D’Argenio DA, Wu M, Hoffman LR, Kulasekara HD, Déziel E, Smith EE, et al. Growth phenotypes of Pseudomonas aeruginosa lasR mutants adapted to the airways of cystic fibrosis patients. Mol Microbiol. (2007) 64:51233. doi: 10.1111/j.1365-2958.2007.05678.x

41. Feltner JB, Wolter DJ, Pope CE, Groleau M-C, Smalley NE, Greenberg $\mathrm{EP}$, et al. LasR Variant cystic fibrosis isolates reveal an adaptable quorum-sensing hierarchy in Pseudomonas aeruginosa. mBio. (2016) 7:e1513. doi: 10.1128/mBio.01513-16

42. Caballero AR, Moreau JM, Engel LS, Marquart ME, Hill JM, O'Callaghan RJ. Pseudomonas aeruginosa protease IV enzyme assays and comparison to other Pseudomonas proteases. Anal Biochem. (2001) 290:330-7. doi: 10.1006/abio.2001.4999

43. Tettmann B, Niewerth C, Kirschhöfer F, Neidig A, Dötsch A, BrennerWeiss G, et al. Enzyme-mediated quenching of the Pseudomonas quinolone signal (PQS) promotes biofilm formation of Pseudomonas aeruginosa by increasing iron availability. Front Microbiol. (2016) 7:1978. doi: $10.3389 /$ fmicb.2016.01978 
44. van 't Wout EFA, van Schadewijk A, van Boxtel R, Dalton LE, Clarke HJ, Tommassen J,et al. Virulence factors of Pseudomonas aeruginosa induce both the unfolded protein and integrated stress responses in airway epithelial cells. PLoS Pathog. (2015) 11:e1004946. doi: 10.1371/journal.ppat.1004946

45. Morihara K, Homma JY. "Pseudomonas proteases," In: Holder I. A, editor. Bacterial Enzymes and Virulence. CRC press (2018) doi: 10.1201/9781351070041-3

46. Ratjen F, Walter H, Haug M, Meisner C, Grasemann H, Döring G. Diagnostic value of serum antibodies in early Pseudomonas aeruginosa infection in cystic fibrosis patients. Pediatr Pulmonol. (2007) 42:249-55. doi: 10.1002/ppul.20562

47. Hollsing AE, Granström M, Vasil ML, Wretlind B, Strandvik B. Prospective study of serum antibodies to Pseudomonas aeruginosa exoproteins in cystic fibrosis. J Clin Microbiol. (1987) 25:1868-74. doi: 10.1128/JCM.25.10.1868-1874.1987

48. Döring G, Høiby N. Longitudinal study of immune response to Pseudomonas aeruginosa antigens in cystic fibrosis. Infect Immun. (1983) 42:197201. doi: 10.1128/IAI.42.1.197-201.1983

49. Mauch RM, Rossi CL, Ribeiro JD, Ribeiro AF, Nolasco da Silva MT, Levy CE. Assessment of IgG antibodies to Pseudomonas aeruginosa in patients with cystic fibrosis by an enzyme-linked immunosorbent assay (ELISA). Diagn Pathol. (2014) 9:158. doi: 10.1186/s13000-014-0158-Z

50. Pilette C, Ouadrhiri Y, Godding V, Vaerman J-P, Sibille Y. Lung mucosal immunity: immunoglobulin-A revisited. Eur Respir J. (2001) 18:57188. doi: 10.1183/09031936.01.00228801

51. Reynolds HY. Immunoglobulin $\mathrm{G}$ and Its function in the human respiratory tract. Mayo Clin Proc. (1988) 63:161-74. doi: 10.1016/S0025-6196(12)64949-0

52. Bomberger JM, Ely KH, Bangia N, Ye S, Green KA, Green WR, et al. Pseudomonas aeruginosa Cif protein enhances the ubiquitination and proteasomal degradation of the transporter associated with antigen processing (TAP) and reduces major histocompatibility complex (MHC) class I antigen presentation. J Biol Chem. (2014) 289:152-62. doi: 10.1074/jbc.M113.459271

53. Folkesson A, Jelsbak L, Yang L, Johansen HK, Ciofu O, Høiby N, et al. Adaptation of Pseudomonas aeruginosa to the cystic fibrosis airway: an evolutionary perspective. Nat Rev Microbiol. (2012) 10:84151. doi: $10.1038 /$ nrmicro2907

54. Boutin S, Weitnauer M, Hassel S, Graeber SY, Stahl M, Dittrich AS, et al. One time quantitative PCR detection of Pseudomonas aeruginosa to discriminate intermittent from chronic infection in cystic fibrosis. J Cyst Fibros. (2018) 17:348-55. doi: 10.1016/j.jcf.2017.12.007

55. Goffard A, Lambert V, Salleron J, Herwegh S, Pinel C, Pin I, et al. Virus and cystic fibrosis: Rhinoviruses are associated with exacerbations in adult patients. J Clin Virol. (2014) 60:147-53. doi: 10.1016/j.jcv.2014.02.005

56. Flight WG, Bright-Thomas RJ, Tilston P, Mutton KJ, Guiver M, Morris J, et al. Incidence and clinical impact of respiratory viruses in adults with cystic fibrosis. Thorax. (2014) 69:247-53. doi: 10.1136/thoraxjnl-2013-204000

57. Talwalkar JS, Murray TS. The approach to Pseudomonas aeruginosa in cystic fibrosis. Clin Chest Med. (2016) 37:69-81. doi: 10.1016/j.ccm.2015.10.004

58. Hendricks MR, Lashua LP, Fischer DK, Flitter BA, Eichinger KM, Durbin JE, et al. Respiratory syncytial virus infection enhances Pseudomonas aeruginosa biofilm growth through dysregulation of nutritional immunity. Proc Natl Acad Sci USA. (2016) 113:1642-7. doi: 10.1073/pnas.1516979113

59. Planet PJ, Parker D, Cohen TS, Smith H, Leon JD, Ryan C, et al. Lambda interferon restructures the nasal microbiome and increases susceptibility to Staphylococcus aureus superinfection. mBio. (2016) 7:e0193915. doi: 10.1128/mBio.01939-15

60. Kuss SK, Best GT, Etheredge CA, Pruijssers AJ, Frierson JM, Hooper LV, et al. Intestinal microbiota promote enteric virus replication and systemic pathogenesis. Science. (2011) 334:249-52. doi: 10.1126/science.1211057

61. Kane M, Case LK, Kopaskie K, Kozlova A, MacDearmid C, Chervonsky $\mathrm{AV}$, et al. Successful transmission of a retrovirus depends on the commensal microbiota. Science. (2011) 334:245-9. doi: 10.1126/science.1210718

62. Pfeiffer JK, Sonnenburg JL. The intestinal microbiota and viral susceptibility. Front Microbiol. (2011) 2:92. doi: 10.3389/fmicb.2011.00092

63. Robinson CM, Jesudhasan PR, Pfeiffer JK. Bacterial lipopolysaccharide binding enhances virion stability and promotes environmental fitness of an enteric virus. Cell Host Microbe. (2014) 15:3646. doi: 10.1016/j.chom.2013.12.004

64. Nygaard RM, Golden JW, Schiff LA. Impact of host proteases on reovirus infection in the respiratory tract. J Virol. (2012) 86:123843. doi: 10.1128/JVI.06429-11

65. Yaghi A, Zaman A, Dolovich M. Primary human bronchial epithelial cells grown from explants. J Vis Exp. (2010) 1789. doi: 10.3791/1789

66. Fulcher ML, Randell SH. Human nasal and tracheo-bronchial respiratory epithelial cell culture. Methods Mol Biol. (2013) 945:109-21. doi: 10.1007/978-1-62703-125-7_8

67. Rahme LG, Stevens EJ, Wolfort SF, Shao J, Tompkins RG, Ausubel FM. Common virulence factors for bacterial pathogenicity in plants and animals. Science. (1995) 268:1899-902. doi: 10.1126/science.7604262

68. Liberati NT, Urbach JM, Miyata S, Lee DG, Drenkard E, Wu G, et al. An ordered, nonredundant library of Pseudomonas aeruginosa strain PA14 transposon insertion mutants. Proc Natl Acad Sci USA. (2006) 103:283338. doi: 10.1073/pnas.0511100103

69. De Boeck K, Derichs N, Fajac I, de Jonge HR, Bronsveld I, Sermet I, et al. New clinical diagnostic procedures for cystic fibrosis in Europe. J Cyst Fibros. (2011) 10(Suppl. 2):S53-66. doi: 10.1016/S1569-1993(11)6 0009-X

Conflict of Interest: The authors declare that the research was conducted in the absence of any commercial or financial relationships that could be construed as a potential conflict of interest.

Copyright (c) 2020 Sörensen, Kantorek, Byrnes, Boutin, Mall, Lasitschka, Zabeck, Nguyen and Dalpke. This is an open-access article distributed under the terms of the Creative Commons Attribution License (CC BY). The use, distribution or reproduction in other forums is permitted, provided the original author(s) and the copyright owner(s) are credited and that the original publication in this journal is cited, in accordance with accepted academic practice. No use, distribution or reproduction is permitted which does not comply with these terms. 